\title{
Biomechanical Evaluation of Oblique Lateral Locking Plate System for Oblique Lumbar Interbody Fusion: A Finite Element Analysis
}

\section{Yinge Wang}

Air Force Medical University 2nd Affiliated Hospital: Air Force Medical University Tangdu Hospital Jiajia Wang

Air Force Medical University 2nd Affiliated Hospital: Air Force Medical University Tangdu Hospital

Sha Tu

Air Force Medical University 2nd Affiliated Hospital: Air Force Medical University Tangdu Hospital

Shuang Li

Air Force Medical University 2nd Affiliated Hospital: Air Force Medical University Tangdu Hospital

Jiangpu Yi

Air Force Medical University 2nd Affiliated Hospital: Air Force Medical University Tangdu Hospital

Haien Zhao

Air Force Medical University 2nd Affiliated Hospital: Air Force Medical University Tangdu Hospital Huanhuan Qiao

Air Force Medical University 2nd Affiliated Hospital: Air Force Medical University Tangdu Hospital

\section{Kang Yan}

Air Force Medical University 2nd Affiliated Hospital: Air Force Medical University Tangdu Hospital Bo Liao ( $\sim$ liaobo@fmmu.edu.cn )

The Second Affiliated Hospital of Air Force Medical University

\section{Research article}

Keywords: Oblique lumbar interbody fusion, Locking, Reverse pedicle track screw, Supplemental fixation, Biomechanical, Finite element analysis

Posted Date: November 22nd, 2021

DOI: https://doi.org/10.21203/rs.3.rs-1077064/v1

License: (c) (1) This work is licensed under a Creative Commons Attribution 4.0 International License. Read Full License 
Version of Record: A version of this preprint was published at World Neurosurgery on January 1st, 2022. See the published version at https://doi.org/10.1016/j.wneu.2021.12.105. 


\section{Abstract}

Objective: Oblique lateral locking plate system (OLLPS) with the locking and reverse pedicle track screw configuration is a novel internal fixation designed for oblique lumbar interbody fusion(OLIF). It is placed in a single-position through the oblique lateral surgical corridor to reduce operative time and subsequent complications of prolonged anesthesia and prone positioning. The purpose of this study was to verify the biomechanical effect of OLLPS.

Methods: The intact finite element model of L1-S1 1 Intact $\triangle$ was established based on CT images of a healthy male volunteer. The L4-L5 intervertebral space was selected as the surgical segment. The surgical models were established separately according to the OLIF surgical procedures and the different internal fixations: (1) stand-alone OLIF (SA); (2) OLIF with 2-screw lateral plate (LP-2); (3) OLIF with 4-screw lateral plate (LP-4); (4) OLIF with OLLPS (OLLPS); and (5) OLIF with bilateral pedicle screw fixation (BPS). After validating the intact model, the physiological loading was applied to the superior surface of L1 to simulate flexion, extension, left bending, right bending, left rotation, and right rotation motions. The evaluation indexes included the L4/5 range of motion (ROM), the L4 maximum displacement, and the maximum stress of the superior and inferior endplate, cage, and supplemental fixation.

Results: In OLIF surgery, OLLPS provided multiplanar stability which was similar to that of BPS. Compared with LP-2 and LP-4, OLLPS had the better biomechanical properties in enhancing the instant stability of the surgical segment, reducing the stress of the superior and inferior endplates of the surgical segment, and reducing the risk of cage subsidence.

Conclsions: With the minimally invasive background, OLLPS can be an alternative to BPS in OLIF and has a better prospect of clinical promotion and application.

\section{Introduction}

Advances in minimally invasive technology open up a new era of spine surgery. Oblique lumbar interbody fusion (OLIF) is widely used in the treatment of degenerative diseases of the lumbar spine because of its advantages such as minimally invasive indirect decompression, efficient interbody fusion and rapid postoperative rehabilitation. The OLIF procedure uses the natural gap between the anterior border of the psoas major and the abdominal vessel to access the lateral aspect of the vertebral body for interbody fusion, eliminating the need for expensive neurological monitoring and allowing multiple segmental fusions with a single small incision using the "sliding window" technique. ${ }^{1}$ The application of large size cage has good results for the correction of spinal force lines, but the high postoperative rate of the cage subsidence is an unavoidable problem. A clinical study by Abe et al. $^{2}$ reported a $9.03 \%$ rate of cage subsidence. However, Zeng et al. ${ }^{3}$ found a subsidence rate up to $19.8 \%$ in patients who underwent standalone OLIF surgery during postoperative follow-up. Indirect decompression failure after cage subsidence may cause a range of clinical symptoms, high reoperation rate, huge financial and health burden. In 
patients with a high risk of cage subsidence, OLIF with supplementary fixation may be a more prudent solution.

Even though OLIF is an effective treatment, there is still no consensus regarding the ideal supplemental fixation. Different fixation methods have been reported in the literature, for example, posterior fixations include pedicle screw fixation, modified cortical bone trajectory (CBT) screws, transfacet screw fixation, and lateral fixations contain anterolateral screw fixation, lateral plate. ${ }^{4-8}$ Bilateral pedicle screw fixation has been regarded as the gold standard, but it may bring about adjacent spondylosis or damage to paravertebral structures. ${ }^{8-10}$ Furthermore, pedicle screw placement requires turning the patient from a lateral to a prone position during surgery and the additional posterior surgical incision, which increases the perioperative risk. The lateral fixation can avoid the induced problems of intraoperative patient flipping and reduce operative time and risk. The shape of lateral plate is more rounded and blunt than the anterolateral screw fixation, which is less invasive to the surrounding tissues and more promising for application. However, the biomechanical stability of the 2-screw lateral plate currently used in OLIF has been questioned, and the acceptance of clinical application is low. ${ }^{11-13}$ We plan to improve the design of the lateral plate to enhance its biomechanical properties. An in vitro biomechanical experiment by DenHaese et al. ${ }^{12}$ confirmed the superior biomechanical properties of the 4 -screw lateral plate compared to the 2-screw lateral plate. In a clinical study, Sardhara et al. ${ }^{14}$ proposed a new theory of reverse pedicle screw fixation (RPSF), which relies on the special trajectory of the lateral screws to achieve 3-column fixation (Fig. 1). We designed the oblique lateral locking plate system (OLLPS) for the OLIF procedure by using the angular stability of the locking screw structure and the RPSF theory, combining the understanding of the connotations of OLIF (Patent No. ZL 202022949889.1). In this study, the biomechanical properties of OLLPS were evaluated to provide a biomechanical basis for its clinical application by establishing 3-dimensional surgical models with various internal fixation and using finite element analysis.

\section{Materials And Methods}

\section{Oblique lateral locking plate system (OLLPS) design}

The oblique lateral locking plate system (OLLPS) consists of a palm-leaf fan-shaped plate and 4 anglespecific locking screws (Fig. 2). The OLLPS is easy to assemble and compatible with OLIF cage, mainly for the L2-L5 intervertebral space. ${ }^{15}$ The OLLPS design is based on the concept of Biological Osteosynthesis for bone trauma. We may consider the superior and inferior bony endplates of the surgical segment as the two ends of the fracture. Accordingly, intervertebral fusion can be considered as the healing of the fracture. The stability of conventional lateral plates is achieved by the friction between the bone surface and the plate. Most of the lumbar vertebral body surfaces have irregular morphology, and the fixable range of the oblique anterior side of the lumbar spine is narrow, resulting in the inability of the conventional lateral plate to closely adhere to the vertebral body. The stress is too concentrated at the contact surface between the screw and the plate, with the risk of the loose screw, broken screw, and 
internal fixation failure. ${ }^{16}$ The OLLPS screws are threaded into the lateral plate at a specific angle, providing angular stability and weight load can be distributed by the screw and lateral plate, which can share the endplate stress. The placement of OLLPS is referenced to a bone trauma locking plate, does not have to closely adhere to the vertebral bone surface, does not require excessive exposure, causes minimal damage to the vertebral periosteum.

The length of the lateral plate is limited by the distance between the superior and inferior segmental artery after the placement of the intervertebral cage. The width of the actual operating area of the surgical corridor is thus a major parameter, determining the width of the plate. The OLIF clinical anatomical studies give us detailed design parameters, and we set the lateral plate width at $22 \mathrm{~mm}$, length at $30 \mathrm{~mm}$ $42 \mathrm{~mm}$ (in $4 \mathrm{~mm}$ increments), and thickness at $5 \mathrm{~mm}$. The overall design of the anatomical lateral plate has a streamlined curved appearance, with a $30^{\circ}$ arc on the coronal and axial positions. The screws are designed as $6.0 \mathrm{~mm}$ diameter solid or hollow cancellous bone screws, and the length is set at $30 \mathrm{~mm}-60$ $\mathrm{mm}$ (in $5 \mathrm{~mm}$ increments). The thread of the screw body is far deep and shallow fishbone spur type tapered thread, which can effectively increase the contact area of the screw/bone interface and increase the screw holding force.

The special trajectory of the screw is the main point of the OLLPS design. Based on the theory of RPSF, we used a 3-dimensional topology optimization method to set the two ventral screws (screws \#1 and \#3 in Fig. 2) to reverse the pedicle trajectory, pointing to the cortical bone area at the junction of the contralateral pedicle and vertebral body, but without penetrating the contralateral bone cortex. However, the space in the region is limited and cannot accommodate multiple screws at the same time, While we design OLLPS to jointly use in multiple segments. Therefore, we adjusted the screw trajectory for topological optimization. Specifically: screws \#1 and \#4 are at an angle of $25^{\circ}$ to the horizontal centerline of the plate (to extend the screw force arm and increase the contact area of the screw/bone interface) and at an angle of $5^{\circ}$ to the vertical centerline of the plate (screw \#1 points to the ventral cortical bone area of the contralateral pedicle region to prevent overlapping of the trajectories of screws \#1 and \#3 of the upper and lower fixation plates when multiple segments are used together); screws \#2 and \#3 are at an angle of $0^{\circ}$ to the horizontal centerline of the plate (parallel to the endplate, increasing the endplate support) and $15^{\circ}$ angle to the vertical centerline of the plate (screw \#3 points to the contralateral pedicle area). Any two screw trajectories are not in the same plane and form an angle with each other, forming a multi-dimensional multi-axial locking.

The plate and screws of OLLPS are made of titanium alloy (Ti6Al4V). The risk of subsidence is minimal when the cage is placed in zones II and III, and OLLPS is also usually placed laterally anterior to the vertebral body corresponding to this. ${ }^{17,18}$ Operators determine the correct orientation of the lateral plate by the non-asymmetric clamping notches on both sides of the plate during the placement operation and use a guide to assist in screw placement based on navigation or fluoroscopic assistance. We recommend that the \#3 reverse pedicle screw should be firstly placed, followed by the oblique contralateral \#2 screw to ensur e that the lateral plate is flat against the surface of the vertebral body, and then the remaining screws are placed in sequence. 


\section{Construction of an intact lumbar finite element model}

A healthy male volunteer (34 years old, weight $70 \mathrm{~kg}$, height $175 \mathrm{~cm}$, no previous lumbar spine disease) was recruited for this study, and 439 images were obtained using GE 64-slice spiral CT for continuous thin-section scanning of the L1-S1 vertebrae (slice thickness $0.625 \mathrm{~mm}$ ) after signing an informed consent. The CT images in Dicom format were sequentially imported into Mimics 23.0 (Materialise Inc., Leuven, Belgium), 3-Matic (Materialise Inc., Leuven, Belgium) software to establish models and perform the smooth restoration. The smoothed model was processed using SolidWorks 2017 CAD (SolidWorks Corporation, Concord, MA, USA) to construct the endplates, annulus fibrosus, nucleus pulposus, and facet joints. The solid model was meshed using HyperMesh (Altair Technologies Inc., Fremont, CA). Finally, ANSYS (Ansys Inc., Canonsburg, PA, USA) was used for material property definition, model assembly, and finite element analysis.

The finite element model (Fig. 3) includes the L1-S1 vertebral body, intervertebral disc and ligament system. The vertebral body includes cortical bone, cancellous bone, bony structures of the posterior column, and endplates, with $1 \mathrm{~mm}$ thick cortical bone and $0.5 \mathrm{~mm}$ thick endplates. ${ }^{19,20} 44 \%$ of the nucleus

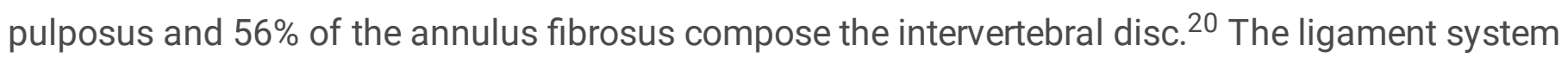
includes the anterior longitudinal ligament, posterior longitudinal ligament, ligamentum flavum, interspinous ligament, supraspinous ligament, capsular ligament, and intertransverse ligament, which were set up as spring elements subjected to tensile loading only. The finite element model was meshed using the tetrahedral and hexahedral elements, except for the ligaments. The mesh size was chosen to be $1.5 \mathrm{~mm}$ after the mesh sensitivity test. The intact model had a total of 511,826 elements and 276,996 nodes. The finite element model was assumed to be a homogeneous, continuous, and isotropic linear elastic material, ${ }^{20}$ and the material properties of the components are shown in Table 1.

Table 1

Material properties used in the finite element models from the literature. ${ }^{11,21-23}$ 


\begin{tabular}{|c|c|c|c|c|}
\hline Structure & $\begin{array}{l}\text { Young's } \\
\text { modulus(MPa) }\end{array}$ & $\begin{array}{l}\text { Poisson' } \\
\text { ratio }\end{array}$ & $\begin{array}{l}\text { Cross- sectional area } \\
\left(\mathrm{mm}^{2}\right)\end{array}$ & $\begin{array}{l}\text { Density } \\
\left(\mathrm{kg} / \mathrm{mm}^{3}\right)\end{array}$ \\
\hline \multicolumn{5}{|l|}{ Bone } \\
\hline Cortical bone & 12,000 & 0.3 & & $1.7 e-6$ \\
\hline Cancellous bone & 100 & 0.2 & & $1.1 \mathrm{e}-6$ \\
\hline Endplate & 500 & 0.25 & & $1.2 \mathrm{e}-6$ \\
\hline \multicolumn{5}{|l|}{ Intervertebral disc } \\
\hline Nucleus pulposus & 1 & 0.49 & & $1.02 \mathrm{e}-6$ \\
\hline Annulus fibrosus & 4.2 & 0.45 & & $1.05 e-6$ \\
\hline \multicolumn{5}{|l|}{ Ligaments } \\
\hline Anterior longitudinal & 20 & 0.3 & 63.7 & $1.0 \mathrm{e}-6$ \\
\hline Posterior longitudinal & 20 & 0.3 & 20 & $1.0 \mathrm{e}-6$ \\
\hline Ligamentum flavum & 19.5 & 0.3 & 40 & $1.0 \mathrm{e}-6$ \\
\hline Interspinous & 11.6 & 0.3 & 40 & $1.0 \mathrm{e}-6$ \\
\hline Supraspinous & 15 & 0.3 & 30 & $1.0 \mathrm{e}-6$ \\
\hline Intertransverse & 58.7 & 0.3 & 3.6 & $1.0 \mathrm{e}-6$ \\
\hline Capsular & 32.9 & 0.3 & 60 & $1.0 \mathrm{e}-6$ \\
\hline \multicolumn{5}{|l|}{ Implants } \\
\hline $\begin{array}{l}\text { Pedicle screws and rods } \\
\text { \Ti-6A1-4V }\end{array}$ & 110,000 & 0.3 & & $4.5 e-6$ \\
\hline $\begin{array}{l}\text { Lateral plate and screws } \\
\qquad \mathrm{Ti}-6 \mathrm{~A} 1-4 \mathrm{~V} \rrbracket\end{array}$ & 110,000 & 0.3 & & $4.5 e-6$ \\
\hline Cage『PEEK囚 & 3500 & 0.3 & & $1.32 \mathrm{e}-6$ \\
\hline
\end{tabular}

\section{Construction of the surgical finite element models}

Cage and internal fixation were performed with a tetrahedral element (Solid187). The L4-L5 intervertebral space was used as the surgical segment, and the annulus fibrosus, nucleus pulposus, and cartilage endplates were removed. On this basis, a stand-alone OLIF (SA) model was constructed based on the CLYDESDALE (Medtronic Sofamor Danek USA, Inc.), with $6^{\circ}$ of anterior convexity, $50 \mathrm{~mm}$ in length, 18 $\mathrm{mm}$ in width, and $12 \mathrm{~mm}$ in anterior height, and made of Polyetheretherketone (PEEK). The internal fixation models were all constructed based on the SA model (Fig. 4). The OLIF with 2-screw lateral plate 
(LP-2) model was constructed based on the Pivox Oblique Lateral Spinal System (Medtronic Sofamor Danek USA, Inc.), in which the plate is $34.6 \mathrm{~mm}$ length, $12 \mathrm{~mm}$ width, $5.4 \mathrm{~mm}$ thickness, and the screws are $45 \mathrm{~mm}$ length and $5.5 \mathrm{~mm}$ outer diameter $\left(15^{\circ}\right.$ angle between the screw and the horizontal centerline of the plate, $0^{\circ}$ angle between the screw and the vertical centerline of the plate). The OLIF with 4-screw lateral plate (LP-4) model was constructed on the basis of the LITe plate system (Stryker USA, Inc.) with the plate length of $28 \mathrm{~mm}$, the width of $21 \mathrm{~mm}$, the thickness of $4.5 \mathrm{~mm}$ and the length of the screws of $45 \mathrm{~mm}, 5.5 \mathrm{~mm}$ outer diameter (the two screws on the ventral side were at an angle of $20^{\circ}$ to the horizontal centerline of the plate, with a vertical centerline angle of $0^{\circ}$ and the two screws on the backside were parallel to the endplate with a vertical centerline angle of $0^{\circ}$ ). The OLIF with oblique lateral locking plate system (OLLPS) model was constructed based on the oblique lateral locking plate system with the plate length of $32 \mathrm{~mm}$, the width of $22 \mathrm{~mm}$, the thickness of $5 \mathrm{~mm}$, and the length of the screws of 45 $\mathrm{mm}, 6.0 \mathrm{~mm}$ external diameter (the screws tilt angle as described previously). The OLIF with bilateral pedicle screw fixation(BPS) model was constructed based on the CDH SEXTANT II (Medtronic Sofamor Danek USA, Inc.) with the pedicle screws diameter of $6.5 \mathrm{~mm}$, length of $45 \mathrm{~mm}$ and the diameter of the rods of $5.5 \mathrm{~mm}$, length over the upper and lower pedicle screw spacing. All materials of internal fixation were titanium alloy (Ti6AI4V), and the material properties of the implants are shown in Table 1.

\section{Contact, boundary and loading conditions}

The connection between the constructed model disc/cage and the superior and inferior endplates was made by means of the no separation contact. The contact surface of the cage and the endplate had a toothed anti-dislocation structure with a friction coefficient of $0.8 .{ }^{24}$ Frictional contact existed between the facet joints, the screw/bone interface, and the interspace between the screws and threaded holes (no sliding between the screws and the threaded holes in the OLLPS model), and the friction coefficient was set at 0.2 to simulate the immediate postoperative state. The inferior surface of the $\mathrm{S} 1$ vertebra was fixed, which means that all nodes of the inferior endplate of the $\mathrm{S} 1$ vertebra were constrained from moving in any direction. A $150 \mathrm{~N}$ axial compressive preload was set on the upper surface of the S1 vertebra to simulate physiological load in upright state, and a pure moment of $10 \mathrm{~N} \cdot \mathrm{m}$ was applied to simulate the model in six directions: (1) flexion (FL); (2) extension (EX); (3) left bending (LB); (4) right bending (RB); (5) left rotation (LR); and (6) right rotation (RR). The L4/5 ROM and maximum displacement of L4 were recorded for all surgical models and compared with the intact model. The maximum stress of the superior and inferior endplates, cage, and supplemental fixation were analyzed in each surgical group. The idealized model of the lumbar spine was symmetrical in the sagittal plane from left to right. The angles of left bending and right bending, left rotation and right rotation should be the same. However, the realistic human lumbar spine does not have $100 \%$ symmetry, and the mobility and stress can vary. ${ }^{25}$ Therefore, the results of the lumbar spine in flexion, extension, left bending, right bending, left rotation, and right rotation were recorded separately in this study.

\section{Results}




\section{Finite Element Model validation}

The L1-S1 segment range of motion (ROM) for different motions of the intact model under a $150 \mathrm{~N}$ axial compression preload and a $10 \mathrm{~N} \cdot \mathrm{m}$ moment load was measured and compared with the outcomes of in the vitro experiment conducted by Yamamoto et al. ${ }^{26}$ (Table 2). The total L1-L5 ROM of the intact model in flexion-extension, lateral bending, and rotational mobility was measured by applying a $7.5 \mathrm{~N} \cdot \mathrm{m}$ moment load and compared with the finite element model investigated in Dreischarf et al. ${ }^{27}$ (Fig. 5A). The L4/5 intervertebral disc pressure (IDP) was tested with pure compressive forces of 300 and $1000 \mathrm{~N}$, which was compared with in vitro experimental data of Brinckmann \& Grootenboer ${ }^{28}$ and the calculated results of the finite element model of Zhang et al. ${ }^{29}$, respectively (Fig. 5B). More segments and approaches were used in our validation than in other similar studies, and the results obtained were in good agreement with those reported in the literature, ensuring the validity of the intact model.

Table 2

The comparison of the ROM between our finite element model and the previous in vitro experimental study.

\begin{tabular}{|c|c|c|c|c|c|c|c|}
\hline $\begin{array}{l}\text { Spinal } \\
\text { levels }\end{array}$ & & Flexion & Extension & $\begin{array}{l}\text { Left } \\
\text { bending }\end{array}$ & $\begin{array}{l}\text { Right } \\
\text { bending }\end{array}$ & $\begin{array}{l}\text { Left } \\
\text { rotation }\end{array}$ & $\begin{array}{l}\text { Right } \\
\text { rotation }\end{array}$ \\
\hline \multirow[t]{2}{*}{ L1-L2 } & $\begin{array}{l}\text { Yamamoto et } \\
\text { al. }{ }^{26}\end{array}$ & $5.8 \pm 0.6$ & $4.3 \pm 0.5$ & $4.7 \pm 0.4$ & $5.2 \pm 0.4$ & $2.6 \pm 0.5$ & $2.0 \pm 0.6$ \\
\hline & Present study & 5.95 & 4.51 & 4.93 & 5.46 & 2.73 & 2.10 \\
\hline \multirow[t]{2}{*}{ L2-L3 } & $\begin{array}{l}\text { Yamamoto et } \\
\text { al. }^{26}\end{array}$ & $6.5 \pm 0.3$ & $4.3 \pm 0.3$ & $7.0 \pm 0.6$ & $7.0 \pm 0.6$ & $2.2 \pm 0.4$ & $3.0 \pm 0.4$ \\
\hline & Present study & 6.72 & 4.52 & 7.35 & 7.35 & 2.31 & 3.15 \\
\hline \multirow[t]{2}{*}{ L3-L4 } & $\begin{array}{l}\text { Yamamoto et } \\
\text { al. }^{26}\end{array}$ & $7.5 \pm 0.8$ & $3.7 \pm 0.3$ & $5.7 \pm 0.3$ & $5.8 \pm 0.5$ & $2.7 \pm 0.4$ & $2.5 \pm 0.4$ \\
\hline & Present study & 7.87 & 3.88 & 5.98 & 6.09 & 2.83 & 2.62 \\
\hline \multirow[t]{2}{*}{ L4-L5 } & $\begin{array}{l}\text { Yamamoto et } \\
\text { al. }{ }^{26}\end{array}$ & $8.9 \pm 0.7$ & $5.8 \pm 0.4$ & $5.5 \pm 0.5$ & $5.9 \pm 0.5$ & $1.7 \pm 0.3$ & $2.7 \pm 0.5$ \\
\hline & Present study & 9.32 & 6.09 & 5.77 & 6.34 & 1.78 & 2.83 \\
\hline \multirow[t]{2}{*}{ L5-S1 } & $\begin{array}{l}\text { Yamamoto et } \\
\text { al. }{ }^{26}\end{array}$ & $10.0 \pm 1.0$ & $7.8 \pm 0.7$ & $5.3 \pm 0.4$ & $5.7 \pm 0.4$ & $1.5 \pm 0.2$ & $1.3 \pm 0.2$ \\
\hline & Present study & 10.45 & 8.19 & 5.56 & 5.98 & 1.57 & 1.36 \\
\hline
\end{tabular}




\section{L4/5 ROM}

Fig. $6 \mathrm{~A}$ shows the results of $L 4 / 5 \mathrm{ROM}$ of the surgical models under the combined loading of $150 \mathrm{~N}$ and $10 \mathrm{~N} \cdot \mathrm{m}$. The ROM was decreased relative to the intact model in all motion modes. Compared with the intact model, SA showed the minimum reduction in mobility with $51.61 \%$ in $\mathrm{FL}, 52.55 \%$ in EX, $55.11 \%$ in LB, $58.83 \%$ in RB, $22.47 \%$ in LR, and $21.91 \%$ in RR. The ROM of the L4/5 segment was further decreased after the placement of the internal fixation. The ROM of LP-2 was decreased by $59.33 \%, 57.96 \%, 69.50 \%$, $66.09 \%, 46.07 \%$, and $41.70 \%$ of the intact model in FL, EX, LB, RB, LR, and RR, respectively. The ability to limit lumbar mobility slightly increased in LP-4 group compared with LP-2 group, but is still inferior to OLLPS and BPS. The ROM of OLLPS was decreased by $73.93 \%, 70.28 \%, 81.28 \%, 79.81 \%, 67.98 \%$, and $65.02 \%$ of the intact model in FL, EX, LB, RB, LR, and RR, respectively. BPSR provided the maximum reduction of ROM compared with the intact for all motions, in which was decreased by $87.66 \%, 85.39 \%$, $79.90 \%, 79.18 \%, 65.17 \%$, and $64.31 \%$ of the intact spine in FL, EX, LB, RB, LR, and RR, respectively. Considering that the most frequent lumbar motions were flexion and extension, BPS had the best overall performance in restricting lumbar motion. Despite this, the restrictive effect of OLLPS on the operated segment was significantly improved relative to LP-2 and LP-4, and the ability to restrict lumbar motion in all directions was higher than $60 \%$, which was comparable to BPS in restricting lateral bending and rotational activities.

\section{L4 Maximum Displacement}

The maximum displacement nephogram of $L 4$ with various fixation options in six motion modes are shown in Fig. 7. The maximum spatial displacement of the superior vertebral body of the surgical segment relative to the inferior vertebral body indirectly reflected the stability of the surgical segment. It may be simply interpreted as the smaller the displacement degree is, the more stable it is. However, the results of relative displacement contained not only the displacement change of the surgical gap but also the displacement increment caused by the vertebral deformation, which was less reliable than ROM, but can be used as an auxiliary criterion for ROM evaluation of lumbar spine stability. ${ }^{30}$ Compared with the intact model, the L4 vertebral displacement in the surgical models was decreased in six motion modes. The data of the three lateral fixation modalities showed a stepwise performance, in short, OLPPS was better than LP-4 and LP-4 was better than LP-2. OLPPS was slightly better than BPS in limiting lumbar motion during lateral bending and rotational movements of the lumbar spine, whereas BPS was better in flexion and extension (Fig. 6B).

\section{Endplate Stress}


Fig. 8 describes the maximum stress in the superior and inferior endplates of the surgical segment. Fig. 9 visualizes the stress distribution of the L5 superior endplate. The maximum stress of the L5 superior endplate in LP-2 group was 3.1366 Mpa, 1.6019 Mpa, 1.7887 Mpa, 1.7381 Mpa, 3.3066 Mpa, and 3.7018 Mpa in FL, EX, LB, RB, LR, and RR, which was decreased by $37.45 \%, 21.51 \%, 47.55 \%, 41.45 \%, 57.14 \%$, and $57.61 \%$ of SA, respectively. The maximum stress of the L5 superior endplate in LP-4 group was decreased by $41.94 \%, 58.65 \%, 59.37 \%, 61.75 \%, 74.72 \%$, and $89.50 \%$ of SA, respectively. The decrease of OLPPS and BPS in endplate stress was greater than that of LP-2 and LP-4. Among all surgical models, OLLPS had the lowest endplate stress of L5 in bending and axial rotation, which was $0.7064 \mathrm{Mpa}$ in left bending, $0.8225 \mathrm{Mpa}$ in right bending, $1.0522 \mathrm{Mpa}$ in left rotation, and $0.7493 \mathrm{Mpa}$ in right rotation, respectively, and the decreases was $79.29 \%, 75.35 \%, 86.36 \%$, and $91.42 \%$ of SA. The maximum stress of L5 endplate of BPS in flexion and extension was the lowest in the surgical model with $2.6235 \mathrm{Mpa}$ and $0.4034 \mathrm{Mpa}$, respectively, which decreased by $47.68 \%$ and $80.23 \%$ compared to SA. The L5 superior endplate stress of OLLPS in lateral bending and axial rotation was slightly lower than that of BPS, which was reduced by $2.0 \%, 7.93 \%, 1.45 \%$, and $7.10 \%$ in LB, RB, LR, and RR, respectively. Fig. 8 shows that the stress of the L5 superior endplate was generally higher than that of the $L 4$ inferior endplate under the same internal fixation and motion conditions. This implied that the risk of cage subsidence is higher in the L 5 superior endplate than in the L4 inferior endplate. This result was consistent with the clinical study by Hu et al. ${ }^{31}$, who found that the subsidence probability of the superior endplate was significantly higher than that of the inferior endplate during the clinical radiographic follow-up of the surgical segment. Fig. 9 clearly shows that the stress of the L5 superior endplate was concentrated in the epiphyseal ring and cortical compact of the vertebral endplate in contact with the cage.

\section{Cage Stress}

Fig. 10A shows the cage stress with various fixation options in six motion modes. The cage stress of SA was maximum in all models, especially in left and right rotation, which was reduced after the implantation of any internal fixation. The cage stress of LP-2 was slightly lower than that of SA, and the cage stress of LP-4 was lower than that of LP-2. Among all surgical models, BPS had the lowest cage stress in the flexion-extension motion state, and OLLPS had the lowest cage stress in the left-right bending and left-right rotation states. In the comparison of BPS, OLLPS had $8.86 \%, 12.56 \%, 3.76 \%$, and $13.85 \%$ lower cage stress in left bending, right bending, left rotation, and right rotation, respectively. Fig. 11 shows the nephogram of the cage stress with various fixation options. The stress distribution was concentrated at the periphery of the cage in all motion states (especially in the dorsal region), which corresponded to the high-stress region of the endplate.

\section{Supplemental Fixation Stress}

The maximum stress of supplemental fixation is shown in Fig. 10B. The maximum stress of OLLPS in FL, EX, LB, RB, LR and RR was 51.899 MPa, 27.206 MPa, 41.478 MPa, 40.127 MPa, 36.143 MPa and 50.483 
MPa, respectively, which were higher than that of LP-2, LP-4 and BPS. The maximum stress of LP-2 appeared in LR and RR, and the maximum values of LP-4, OLLPS and BPS appeared in FL and RR. Further analysis reveals that the maximum stress of LP-2 and BPS occurred the interface between the superior screw and the bone, and the maximum stress of OLLPS occurred in the plate (Fig. 12). OLLPS was endured higher stress than other internal fixations, but was far below than the fatigue strength 310$610 \mathrm{MPa}$ and yield strength 789-1013 MPa reported in the literature for titanium internal fixation. ${ }^{16}$ The maximum stress of BPS was smooth in all motions, and there was no sudden increase in stress in one motion mode, suggesting a balanced biomechanical performance in all directions of motion of the lumbar spine.

\section{Discussion}

Biomechanical properties are the important element of the novel internal fixation research. There are two mainstream biomechanical assessment methods: one is in vitro cadaveric biomechanical experiments; the other is finite element analysis. In vitro cadaver biomechanical experiments are difficult to implement because of the strict requirements for cadaver conditions and laboratory equipment. With the advancement of finite element analysis technology, the reconstruction of finite element models for the lumbar spine based on normal human CT images has become the accepted method for biomechanical analysis. Through the simulation of different internal fixation models, the comparative analysis of the activity of surgical segments and the stress characteristics of each structure after applying physiological load can help us understand the biomechanical characteristics of the current internal fixation methods. In the study, the biomechanical properties of the combined application of OLLPS and OLIF were discussed for the first time. We innovatively introduced the concept of Biological Osteosynthesis for bone trauma into vertebral fusion and introduced the angle stabilization structure and reverse pedicle screw trajectory design on the basis of conventional lateral plate fixation to improve the stability of OLLPS.

The retrospective study by Silvestre et al. ${ }^{15}$ firstly named and discussed the OLIF procedure. 179 patients who underwent OLIF were included in his study, the results indicate that a mean intraoperative bleeding of $56.8 \pm 131.3 \mathrm{~mL}$, a mean operative time of $32.5 \pm 13.2 \mathrm{~min}$, and postoperative complications mainly consisting of incisional pain (4 cases, $2.2 \%$ ) and lower extremity symptoms due to sympathetic nerve chain injury (3 cases, 1.7\%). Compared with PLIF in traditional posterior open surgery, OLIF had significant advantages such as a smaller surgical incision, shorter anesthesia time, less intraoperative bleeding, less postoperative pain, and faster postoperative recovery. ${ }^{32}$ Compared with MIS-TLIF, a posterior minimally invasive procedure, OLIF can provide better correction of sagittal parameters and clinical outcomes, more satisfactory restoration of vertebral space height, and earlier intervertebral fusion. ${ }^{33-36}$ During the clinical applications of lumbar interbody fusion, the importance of the posterior lumbar ligamentous complex for maintaining spinal stability has been increasingly recognized. ${ }^{37}$ The reports of postoperative intractable low back pain caused by the injuries of bony structures, muscles, and ligaments in the posterior lumbar region were also common. Stand-alone OLIF can minimize structural damage to the posterior lumbar spine. $8,38,39$ However, cage subsidence has been a problem in the stand- 
alone technique. The clinical application effects and complications of stand-alone OLIF can be explained in biomechanical studies. According to the mechanism of fracture healing, the relative stability of the fracture end is a prerequisite for healing. Our study suggested that SA had the least decrease of ROM in all motion modes and internal fixation modalities, which resulting in the least ability to maintain lumbar spine stability. Our results were consistent with the in vitro biomechanical findings by Laws et al. ${ }^{40}$ The reduction of ROM in SA flexion-extension and lateral bending mode is better in rotation mode, which is associated with the design of the fusion cage convex angle and the transverse placement of the lumbar coronal line.

The purpose of supplemental fixation for lumbar fusion is to stabilize the lumbar spine, reduce the mobility of the surgical segment, create a stable external environment for fusion, share the stress of the endplate, and reduce the incidence of cage subsidence. ${ }^{11}$ The results of this study suggested that all fixation modalities enhanced the stability of the lumbar spine structure compared to the SA model, but the degree of stability varied considerably in the different supplemental fixation modalities. BPS had the greatest ability to maintain the stability of the lumbar spine in the immediate postoperative period. However, in our opinion, the effect of the combination of OLIF with BPS is $1+1<2$. As mentioned, the damage to the posterior lumbar structures associated with posterior internal fixation plays a subtractive role. Re-positioning to the prone position is traditionally required for placing BPS, which extends operative time by an average of 45 to 60 minutes. ${ }^{41}$ Prolonged anesthesia in the prone position leaves patients at risk for complications, such as increased blood loss, peripheral nerve injuries, difficulties in airway access and postoperative infection. ${ }^{42,43}$ The design of OLLPS is based on the idea that $1+1>2$. OLLPS is placed in a single-position through the oblique lateral surgical corridor to give full advantage to the OLIF procedure for non-injury to the posterior lumbar structures and reduce operative time and subsequent complications of prolonged anesthesia and prone positioning. The lateral plate has an inherent deficiency in achieving bilateral equalization, but the big size cage crossing the epiphysis ring can diminish this deficiency. Previous studies showed that lateral plate increased the stiffness of the lumbar spine in bending and rotation but had little effect in flexion and extension. ${ }^{11,40,44}$ In our study, lateral fixations of LP-2, LP-4, and OLLPS were more restrictive for lumbar lateral bending and axial rotation. In the treatment of long bong fracture, locking plate systems have been proved to have significant advantages in stability and bone regeneration. ${ }^{45}$ Our findings suggest that the idea of angular stability is also beneficial in lateral plate. OLLPS demonstrated superior stability in lateral bending and axial rotation following implantation. The junctions between the screws and the plate of LP-2 and LP-4 are equivalent to a rotatable portal axis, and as the lumbar spine move, the screws and the plate can rotate relative to each other, especially in flexion and extension. The locking structure of OLLPS combines the screws with the plate as a single unit, with all the screws and plate acting synergistically to counteract lumbar motion, and the plate does not need to be pressed against the vertebral bone surface, thus protecting the periosteal blood supply. The multidimensional angular stabilization layout of the OLLPS screws and the plate/screws locking structure an improved its ability to limit lumbar flexion and extension compared with the existing lateral internal fixation LP-2 and LP-4. The screws of OLLPS have a thicker diameter than that of LP-2 and LP-4, and the special inclined trajectory and surface threads of the screws increase the 
contact area of the screw-bone to provide a tighter bond with cancellous bone, which improves the holding power and fixation of the OLLPS on the vertebral body. Screw-locked structural stability was not significantly decreased in the osteoporotic patients. ${ }^{46}$ The different biomechanical behavior depends on the direction of loads acting on the screws. ${ }^{46}$ For motion in flexion/extension, the longitudinal axis of the OLLPS screws intersects the lumbar rotation axis at a small angle, while the BPS is orthogonal to the rotation axis. The torque of OLLPS screws against lumbar flexion and extension is less than the BPS. Therefore, the OLLPS is less capable of limiting lumbar flexion/extension than the BPS. For lateral bending and axial rotational motion, the longitudinal axis of the OLLPS screws is orthogonal to the rotation axis, and the reverse pedicle screw trajectory gives it a longer lever arm for resisting lumbar motion. Therefore, the OLLPS is comparable to the BPS in limiting lumbar lateral bending and rotational activity. In our study, the results of the maximum displacement of the superior vertebral body corroborated with the ROM results of the surgical segment.

It had been reported that cage subsidence was closely related to the endplate stress and cage stress of the fused segment. ${ }^{47,48}$ According to the stress-growth curve of the vertebral body cells, the higher the compressive stress is, the more inhibited the growth of vertebral body cells is. ${ }^{49}$ The bone density of the epiphyseal ring at the periphery of the vertebral endplate was much higher than that of the central region of the endplate, which providing the greatest resistance to cage subsidence. ${ }^{50}$ During the fusion process of the OLIF, the epiphyseal ring and cortical compact have the effect of supporting the cage, and the cancellous bone contributes to the fusion with the intervertebral cage. A longer and wider cage has larger contact area, more dispersed stress and lower subsidence risk. ${ }^{51-53}$ Although compared with traditional banana-shaped or bullet-shaped cages, the cage of stand-alone OLIF across the epiphyseal ring of endplate reduces the risk subsidence. However, without supplementary fixations, the weight load may be distributed directly on the cage and endplate surfaces, increasing the possibility of endplate collapse and cage subsidence, and the protentional complications associated with endplate collapse and cage subsidence remain a concern, especially in osteoporotic patients. ${ }^{13,54}$ The results of Zhang et al. ${ }^{11}$ showed that the lateral plate can reduce the stress of the fusion cage and the endplate when the lumbar lateral bending, but it has little effect in other motion modes. A recent FEA article reported that LP-2 significantly reduced cage and endplate stress in lateral bending and axial rotation. ${ }^{13}$ Our results showed that when LP-2 was implanted, the endplate and cage stress decreased in a stepwise manner and the risk of cage subsidence was reduced compared with the SA model. The L 5 endplate stress of OLLPS decreased by $43.82 \%-91.42 \%$ of SA, which was better than that of LP-2 and LP-4. The decrease of OLLPS was similar to that of BPS in lateral bending and rotational modes, and the risk of cage subsidence was low, but the stress sharing in flexion and extension was less than that of BPS. According to the stress transmission mechanism of angle-stabilized structures, the locking screws form a fixed angle with the plate, which facilitates the transfer of stress from the screws to the plate. ${ }^{55}$ Compared with traditional screws, all locking screws acted synergistically to resist stresses like a single-beam structure, which could distribute the load uniformly on the plate. ${ }^{56}$ Our results show that the OLLPS internal fixational stress is larger than other internal fixations, mainly concentrated in the titanium plate, rather than the screw-bone 
contact, and is far lower than the titanium fatigue strength and yield strength of titanium alloy. Our model simulates the immediate postoperative state, and the internal fixation stress would be further reduced with the completion of fusion.

There is no lateral locking plate designed for the OLIF procedure on the market, and the related research is still in a blank state. The OLLPS we studied is minimally invasive and inserted through the OLIF approach to avoid soft tissue injuries such as dorsal muscles, ligaments, and articular capsules. Sardhara et al. ${ }^{14}$ has demonstrated the feasibility of RPSF using the 2-screw lateral plate in clinical cases. Gragnaniello et al. ${ }^{57}$ also reported good clinical results by applying OLIF combined with the 4-screw lateral plate in patients with good bone density. Compared with LP-2 and LP-4, OLLPS could better maintain the immediate stability of the surgical segment, effectively reduce the stress of the superior and inferior endplates of the surgical segment, and reduce the risk of cage subsidence. In lateral bending and axial rotation, OLLPS is slightly better than BPS in reducing the stress of the surgical segment endplate and the fusion cage. The ability of OLLPS to limit lumbar flexion and extension is not good as that of BPS. In clinical practice, we routinely recommend that patients wear a lumbar brace after lumbar interbody fusion surgery. Some studies have reported that lumbar braces can restrict lumbar sagittal motion well, which could compensate for the OLLPS limitation of lumbar mobilities and expand the clinical applicability of OLLPS. ${ }^{58,59}$ The OLLPS angular stabilization structure transfers body loads directly to the lateral plate via screws, allowing early weight-bearing of the surgical segment with no risk of fixation failure at the plate/screw junction and facilitating early patient recovery. ${ }^{60}$ Certainly, the superiority of OLLPS is balanced with its relatively difficult implantation technology. The use of multi-axis screws can be considered to facilitate the implantation operation through their adaptability and multi-directional screw trajectory.

Our study had some limitations. Firstly, our model did not reconstruct the paravertebral soft tissues to assess the effect of muscle on spinal biomechanical function, which was a common problem faced by all finite element analysis. Secondly, we did not assess the effects of osteoporosis and bone loss, because different degrees of BMD may have different results. Moreover, the model was limited to detect the instant features of static biomechanics after surgery. Despite the limitations existed, in this study we applied more comprehensive methods to validate the validity of the finite element model than in previous studies, and simulations of different internal fixation modalities were performed under the same experimental conditions. Therefore, our model was valid to evaluate the biomechanical properties of OLLPS.

\section{Conclusions}

Our study confirms that the locking structure and the reverse pedicle track screw can enhance the biomechanical properties of the lateral plate. OLLPS was superior to LP-2 and LP-4 in maintaining postoperative lumbar stability and reducing endplate and cage stress. OLLPS provided multiplanar stability similar to that of BPS and had a slightly better ability to reduce endplate and fusion stress during lumbar lateral bending and rotational activities than BPS. OLLPS is designed to save more patients from 
additional injury, which has good prospects for promotion and research, but extensive in vitro and clinical trials will need to demonstrate the application effect. In addition, more innovative techniques and instruments will need to facilitate the OLLPS placement operation, and its mechanical properties, such as long-term stability and fatigue resistance, need to be further investigated.

\section{Abbreviations}

BMD: Bone Mineral Density; BPS: OLIF with bilateral pedicle screw fixation; CBT: cortical bone trajectory screws; EX: extension; FL: flexion; IDP: intervertebral disc pressure; LB: left bending; LR: left rotation; LP-2: 2-screw lateral plate; LP-4: OLIF with 4-screw lateral plate; MIS-TLIF: minimally invasive transforaminal lumbar interbody fusion; OLLPS: Oblique lateral locking plate system; OLIF: oblique lumbar interbody fusion; PLIF: posterior lumbar interbody fusion; PEEK: Polyetheretherketone; ROM: range of motion; RPSF: reverse pedicle screw fixation; RB: right bending; RR: right rotation; SA: stand-alone OLIF

\section{Declarations}

\section{Acknowledgments}

We would like to thank Mr. Chen for computer technique support (Xi'an Jing An Mei Computer Technology Co., Ltd).

\section{Authors' contributions}

Yinge Wang: Project administration, Supervision, Data curation, Writing - original draft, Writing - review \& editing. Jiajia Wang: Methodology, Resources, Data curation, Writing - review \& editing. Sha Tu: Data curation. Shuang Li: Data curation. Jiangpu Yi: Formal analysis, Data curation. Haien Zhao: Project administration, Writing - review \& editing. Huanhuan Qiao: Project administration. Kang Yan: Project administration, Funding acquisition, Supervision, Resources, Writing - review \& editing. Bo Liao: Funding acquisition, Supervision, Writing - review \& editing.

\section{Funding}

This study was funded by Innovation Capability Support Program of Shaanxi(Program No: 2021TD-45).

\section{Availability of data and materials}

The datasets used and/or analyzed during the current study are available from the corresponding author on reasonable request. 


\section{Ethical Considerations}

This finite element analysis did not require approval by an institutional review board.

\section{Consent for publication}

Not applicable.

\section{Competing interests}

All authors declare that they have no competing interests.

\section{References}

1. Lee HJ, Ryu KS, Hur JW, Seong JH, Cho HJ, Kim JS. Safety of Lateral Interbody Fusion Surgery without Intraoperative Monitoring. Turk Neurosurg. 2018;28(3):428-433. doi:10.5137/10195149.Jtn.20103-17.1

2. Abe K, Orita S, Mannoji C, et al. Perioperative Complications in 155 Patients Who Underwent Oblique Lateral Interbody Fusion Surgery: Perspectives and Indications From a Retrospective, Multicenter Survey. Spine (Phila Pa 1976). Jan 1 2017;42(1):55-62. doi:10.1097/brs.0000000000001650

3. Zeng ZY, Xu ZW, He DW, et al. Complications and Prevention Strategies of Oblique Lateral Interbody Fusion Technique. Orthop Surg. May 2018;10(2):98-106. doi:10.1111/os.12380

4. Wu JY, Yuan Q, Liu YJ, Sun YQ, Zhang Y, Tian W. Robot-assisted Percutaneous Transfacet Screw Fixation Supplementing Oblique Lateral Interbody Fusion Procedure: Accuracy and Safety Evaluation of This Novel Minimally Invasive Technique. Orthop Surg. Feb 2019;11(1):25-33. doi:10.1111/os.12428

5. Woods KR, Billys JB, Hynes RA. Technical description of oblique lateral interbody fusion at L1-L5 (OLIF25) and at L5-S1 (OLIF51) and evaluation of complication and fusion rates. Spine J. Apr 2017;17(4):545-553. doi:10.1016/j.spinee.2016.10.026

6. Beng TB, Kotani Y, Sia U, Gonchar I. Effect of Indirect Neural Decompression with Oblique Lateral Interbody Fusion Was Influenced by Preoperative Lumbar Lordosis in Adult Spinal Deformity Surgery. Asian Spine J. Oct 2019;13(5):809-814. doi:10.31616/asj.2018.0283

7. Tohmeh AG, Khorsand D, Watson B, Zielinski X. Radiographical and clinical evaluation of extreme lateral interbody fusion: effects of cage size and instrumentation type with a minimum of 1-year follow-up. Spine (Phila Pa 1976). Dec 15 2014;39(26):E1582-91.

doi:10.1097/brs.0000000000000645 
8. He W, He D, Sun Y, et al. Quantitative analysis of paraspinal muscle atrophy after oblique lateral interbody fusion alone vs. combined with percutaneous pedicle screw fixation in patients with spondylolisthesis. BMC Musculoskelet Disord. Jan 14 2020;21(1):30. doi:10.1186/s12891-020-30519

9. Du CF, Cai XY, Gui W, et al. Does oblique lumbar interbody fusion promote adjacent degeneration in degenerative disc disease: A finite element analysis. Comput Biol Med. Jan 2021;128:104122. doi:10.1016/j.compbiomed.2020.104122

10. Kang K-T, Kim H-J, Son J, Yeom JS, Chun H-J. Comparing an instrumented posterior fixation system with rigid and semi-flexible rods using finite element analysis. International Journal of Precision Engineering and Manufacturing. 2015/01/01 2015;16(1):163-170. doi:10.1007/s12541-015-0021-5

11. Zhang Z, Fogel GR, Liao Z, Sun Y, Liu W. Biomechanical Analysis of Lateral Lumbar Interbody Fusion Constructs with Various Fixation Options: Based on a Validated Finite Element Model. World Neurosurg. Jun 2018;114:e1120-e1129. doi:10.1016/j.wneu.2018.03.158

12. DenHaese R, Gandhi A, Ferry C, Farmer S, Porter R. An In Vitro Biomechanical Evaluation of a Lateral Lumbar Interbody Fusion Device With Integrated Lateral Modular Plate Fixation. Global Spine J. Apr 2021;11(3):351-358. doi:10.1177/2192568220905611

13. Song C, Chang H, Zhang D, Zhang Y, Shi M, Meng X. Biomechanical Evaluation of Oblique Lumbar Interbody Fusion with Various Fixation Options: A Finite Element Analysis. Orthop Surg. Apr 2021;13(2):517-529. doi:10.1111/os.12877

14. Sardhara J, Singh S, Mehrotra A, et al. Neuro-navigation assisted pre-psoas minimally invasive oblique lumbar interbody fusion (MI-OLIF): New roads and impediments. Neurol India. May-Jun 2019;67(3):803-812. doi:10.4103/0028-3886.263262

15. Silvestre C, Mac-Thiong JM, Hilmi R, Roussouly P. Complications and Morbidities of Mini-open Anterior Retroperitoneal Lumbar Interbody Fusion: Oblique Lumbar Interbody Fusion in 179 Patients. Asian Spine J. Jun 2012;6(2):89-97. doi:10.4184/asj.2012.6.2.89

16. Dong E, Shi L, Kang J, et al. Biomechanical characterization of vertebral body replacement in situ: Effects of different fixation strategies. Comput Methods Programs Biomed. Dec 2020;197:105741. doi:10.1016/j.cmpb.2020.105741

17. Shiga $Y$, Orita S, Inage $K$, et al. Evaluation of the location of intervertebral cages during oblique lateral interbody fusion surgery to achieve sagittal correction. Spine surgery and related research. 2017;1(4):197-202. doi:10.22603/ssrr.1.2017-0001

18. Park SJ, Lee CS, Chung SS, Kang SS, Park HJ, Kim SH. The Ideal Cage Position for Achieving Both Indirect Neural Decompression and Segmental Angle Restoration in Lateral Lumbar Interbody Fusion (LLIF). Clinical spine surgery. Jul 2017;30(6):E784-e790. doi:10.1097/bsd.0000000000000406

19. Zhou QK, Zeng FH, Tu JL, Dong ZQ, Ding ZH. Influence of cement-augmented pedicle screw instrumentation in an osteoporotic lumbosacral spine over the adjacent segments: a 3D finite element study. J Orthop Surg Res. Apr 7 2020;15(1):132. doi:10.1186/s13018-020-01650-5 
20. Liu X, Ma J, Park P, Huang X, Xie N, Ye X. Biomechanical comparison of multilevel lateral interbody fusion with and without supplementary instrumentation: a three-dimensional finite element study. BMC Musculoskelet Disord. Feb 2 2017;18(1):63. doi:10.1186/s12891-017-1387-6

21. Shen H, Chen Y, Liao Z, Liu W. Biomechanical evaluation of anterior lumbar interbody fusion with various fixation options: Finite element analysis of static and vibration conditions. Clin Biomech (Bristol, Avon). Apr 2021;84:105339. doi:10.1016/j.clinbiomech.2021.105339

22. Kumaran $Y$, Shah $A$, Katragadda $A$, et al. latrogenic muscle damage in transforaminal lumbar interbody fusion and adjacent segment degeneration: a comparative finite element analysis of open and minimally invasive surgeries. Eur Spine J. Jul 14 2021;doi:10.1007/s00586-021-06909-x

23. Guo LX, Wang QD. Comparison of effects of four interbody fusion approaches on the fused and adjacent segments under vibration. Clin Biomech (Bristol, Avon). Jun 2020;76:105023. doi:10.1016/j.clinbiomech.2020.105023

24. Areias B, Caetano SC, Sousa LC, et al. Numerical simulation of lateral and transforaminal lumbar interbody fusion, two minimally invasive surgical approaches. Comput Methods Biomech Biomed Engin. Jun 2020;23(8):408-421. doi:10.1080/10255842.2020.1734579

25. Sawa AGU, Lehrman JN, Crawford NR, Kelly BP. Variations Among Human Lumbar Spine Segments and Their Relationships to In Vitro Biomechanics: A Retrospective Analysis of 281 Motion Segments From 85 Cadaveric Spines. Int J Spine Surg. Apr 2020;14(2):140-150. doi:10.14444/7021

26. Yamamoto I, Panjabi MM, Crisco T, Oxland T. Three-dimensional movements of the whole lumbar spine and lumbosacral joint. Spine (Phila Pa 1976). Nov 1989;14(11):1256-60.

doi:10.1097/00007632-198911000-00020

27. Dreischarf M, Zander T, Shirazi-Adl A, et al. Comparison of eight published static finite element models of the intact lumbar spine: predictive power of models improves when combined together. $J$ Biomech. Jun 3 2014;47(8):1757-66. doi:10.1016/j.jbiomech.2014.04.002

28. Brinckmann P, Grootenboer $\mathrm{H}$. Change of disc height, radial disc bulge, and intradiscal pressure from discectomy. An in vitro investigation on human lumbar discs. Spine (Phila Pa 1976). Jun 1991;16(6):641-6. doi:10.1097/00007632-199106000-00008

29. Zhang Y, Li Y, Xue J, et al. Combined Effects of Graded Foraminotomy and Annular Defect on Biomechanics after Percutaneous Endoscopic Lumbar Decompression: A Finite Element Study. J Healthc Eng. 2020;2020:8820228. doi:10.1155/2020/8820228

30. Eskandari AH, Arjmand N, Shirazi-Adl A, Farahmand F. Hypersensitivity of trunk biomechanical model predictions to errors in image-based kinematics when using fully displacement-control techniques. $J$ Biomech. Feb 14 2019;84:161-171. doi:10.1016/j.jbiomech.2018.12.043

31. Hu Z, He D, Gao J, et al. The Influence of Endplate Morphology on Cage Subsidence in Patients With Stand-Alone Oblique Lateral Lumbar Interbody Fusion (OLIF). Global Spine J. Mar 9 2021:2192568221992098. doi:10.1177/2192568221992098

32. Wu M, Li J, Zhang M, et al. Efficacy and radiographic analysis of oblique lumbar interbody fusion for degenerative lumbar spondylolisthesis. J Orthop Surg Res. Nov 28 2019;14(1):399. 
doi:10.1186/s13018-019-1416-2

33. Lin GX, Akbary K, Kotheeranurak V, et al. Clinical and Radiologic Outcomes of Direct Versus Indirect Decompression with Lumbar Interbody Fusion: A Matched-Pair Comparison Analysis. World Neurosurg. Nov 2018;119:e898-e909. doi:10.1016/j.wneu.2018.08.003

34. Sheng SR, Geng YB, Zhou KL, Wu AM, Wang XY, Ni WF. Minimally invasive surgery for degenerative spondylolisthesis: transforaminal or oblique lumbar interbody fusion. J Comp Eff Res. Jan 2020;9(1):45-51. doi:10.2217/cer-2019-0055

35. Zhang C, Wang K, Jian F, Wu H. Efficacy of Oblique Lateral Interbody Fusion in Treatment of Degenerative Lumbar Disease. World Neurosurg. Nov 24 2018;doi:10.1016/j.wneu.2018.11.139

36. Liu J, He Y, Huang B, et al. Reoccurring discogenic low back pain (LBP) after discoblock treated by oblique lumbar interbody fusion (OLIF). J Orthop Surg Res. Jan 20 2020;15(1):22. doi:10.1186/s13018-020-1554-6

37. Izzo R, Guarnieri G, Guglielmi G, Muto M. Biomechanics of the spine. Part I: spinal stability. Eur J Radiol. Jan 2013;82(1):118-26. doi:10.1016/j.ejrad.2012.07.024

38. Blizzard DJ, Thomas JA. MIS Single-position Lateral and Oblique Lateral Lumbar Interbody Fusion and Bilateral Pedicle Screw Fixation: Feasibility and Perioperative Results. Spine (Phila Pa 1976). Mar 15 2018;43(6):440-446. doi:10.1097/brs.0000000000002330

39. Huo Y, Yang D, Ma L, Wang H, Ding W, Yang S. Oblique Lumbar Interbody Fusion with Stand-Alone Cages for the Treatment of Degenerative Lumbar Spondylolisthesis: A Retrospective Study with 1Year Follow-Up. Pain Res Manag. 2020;2020:9016219. doi:10.1155/2020/9016219

40. Laws CJ, Coughlin DG, Lotz JC, Serhan HA, Hu SS. Direct lateral approach to lumbar fusion is a biomechanically equivalent alternative to the anterior approach: an in vitro study. Spine (Phila Pa 1976). May 1 2012;37(10):819-25. doi:10.1097/BRS.0b013e31823551aa

41. Ziino C, Konopka JA, Ajiboye RM, Ledesma JB, Koltsov JCB, Cheng I. Single position versus lateralthen-prone positioning for lateral interbody fusion and pedicle screw fixation. J Spine Surg. Dec 2018;4(4):717-724. doi:10.21037/jss.2018.12.03

42. DePasse JM, Palumbo MA, Haque M, Eberson CP, Daniels AH. Complications associated with prone positioning in elective spinal surgery. World J Orthop. Apr 18 2015;6(3):351-9.

doi:10.5312/wjo.v6.i3.351

43. Olsen MA, Nepple JJ, Riew KD, et al. Risk factors for surgical site infection following orthopaedic spinal operations. The Journal of bone and joint surgery American volume. Jan 2008;90(1):62-9. doi:10.2106/jbjs.F.01515

44. Cappuccino A, Cornwall GB, Turner AW, et al. Biomechanical analysis and review of lateral lumbar fusion constructs. Spine (Phila Pa 1976). Dec 15 2010;35(26 Suppl):S361-7. doi:10.1097/BRS.0b013e318202308b

45. Augat $P$, von Rüden C. Evolution of fracture treatment with bone plates. Injury. Jun 2018;49 Suppl 1:S2-s7. doi:10.1016/s0020-1383(18)30294-8 
46. Disch AC, Knop C, Schaser KD, Blauth M, Schmoelz W. Angular stable anterior plating following thoracolumbar corpectomy reveals superior segmental stability compared to conventional polyaxial plate fixation. Spine (Phila Pa 1976). Jun 1 2008;33(13):1429-37.

doi:10.1097/BRS.0b013e318175c342

47. Tsai PI, Hsu CC, Chen SY, Wu TH, Huang CC. Biomechanical investigation into the structural design of porous additive manufactured cages using numerical and experimental approaches. Comput Biol Med. Sep 1 2016;76:14-23. doi:10.1016/j.compbiomed.2016.06.016

48. Chatham LS, Patel VV, Yakacki CM, Dana Carpenter R. Interbody Spacer Material Properties and Design Conformity for Reducing Subsidence During Lumbar Interbody Fusion. J Biomech Eng. May 1 2017;139(5):0510051-8. doi:10.1115/1.4036312

49. Bylski-Austrow DI, Glos DL, Wall EJ, Crawford AH. Scoliosis vertebral growth plate histomorphometry: Comparisons to controls, growth rates, and compressive stresses. J Orthop Res. Sep 2018;36(9):2450-2459. doi:10.1002/jor.23900

50. Zhang $X$, Wu H, Chen Y, et al. Importance of the epiphyseal ring in OLIF stand-alone surgery: a biomechanical study on cadaveric spines. Eur Spine J. Jan 2021;30(1):79-87. doi:10.1007/s00586020-06667-2

51. Liu C, Zhai J, Yuan Q, Zhang Y, Xu H. A patient with left-sided inferior vena cava who received oblique lumbar interbody fusion surgery: a case report. J Med Case Rep. Jan 27 2020;14(1):21. doi:10.1186/s13256-020-2342-y

52. Marchi L, Abdala N, Oliveira L, Amaral R, Coutinho E, Pimenta L. Radiographic and clinical evaluation of cage subsidence after stand-alone lateral interbody fusion. J Neurosurg Spine. Jul 2013;19(1):110-8. doi:10.3171/2013.4.Spine12319

53. Chen YL, Lai OJ, Wang Y, Ma WH, Chen QX. The biomechanical study of a modified lumbar interbody fusion-crenel lateral interbody fusion (CLIF): a three-dimensional finite-element analysis. Comput Methods Biomech Biomed Engin. Jul 2020;23(9):548-555. doi:10.1080/10255842.2020.1745784

54. Lu T, Lu Y. Comparison of Biomechanical Performance Among Posterolateral Fusion and Transforaminal, Extreme, and Oblique Lumbar Interbody Fusion: A Finite Element Analysis. World Neurosurg. Sep 2019;129:e890-e899. doi:10.1016/j.wneu.2019.06.074

55. Beltran MJ, Collinge CA, Gardner MJ. Stress Modulation of Fracture Fixation Implants. J Am Acad Orthop Surg. Oct 2016;24(10):711-9. doi:10.5435/jaaos-d-15-00175

56. Gautier E, Perren SM, Cordey J. Effect of plate position relative to bending direction on the rigidity of a plate osteosynthesis. A theoretical analysis. Injury. Sep 2000;31 Suppl 3:C14-20. doi:10.1016/s0020-1383(00)80027-3

57. Gragnaniello C, Seex K. Anterior to psoas (ATP) fusion of the lumbar spine: evolution of a technique facilitated by changes in equipment. J Spine Surg. Dec 2016;2(4):256-265. doi:10.21037/jss.2016.11.02

58. Norrie JP, Brown SHM. Brace yourself: How abdominal bracing affects intersegmental lumbar spine kinematics in response to sudden loading. J Electromyogr Kinesiol. Oct 2020;54:102451. 
doi:10.1016/j.jelekin.2020.102451

59. Jegede KA, Miller CP, Bible JE, Whang PG, Grauer JN. The effects of three different types of orthoses on the range of motion of the lumbar spine during 15 activities of daily living. Spine (Phila Pa 1976). Dec 15 2011;36(26):2346-53. doi:10.1097/BRS.0b013e31820921a5

60. Bel JC. Pitfalls and limits of locking plates. Orthop Traumatol Surg Res. Feb 2019;105(1s):S103s109. doi:10.1016/j.otsr.2018.04.031

\section{Figures}

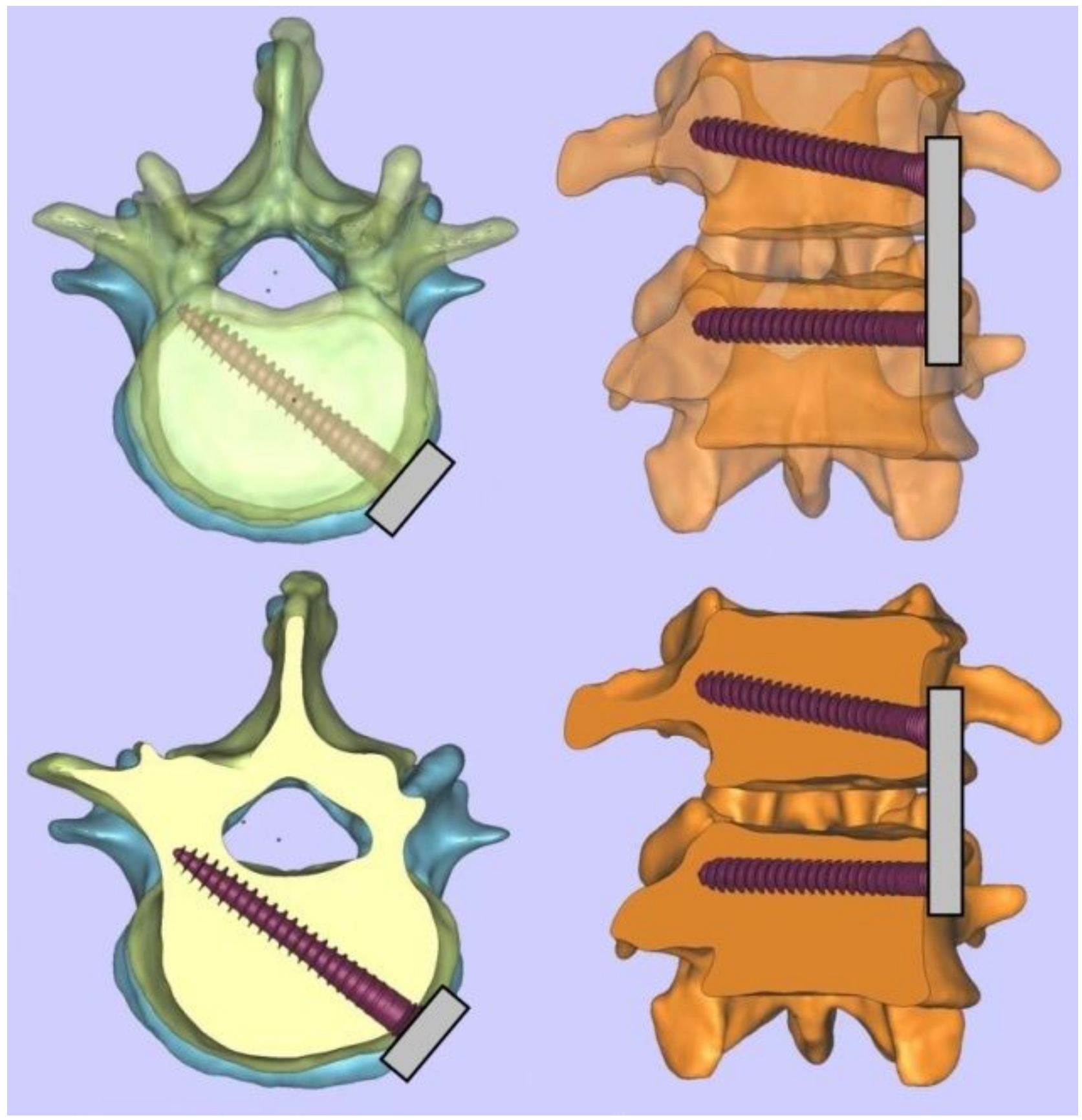

Figure 1 
The novel concept of lateral lumbar fixation through reverse pedicle screw (RPSF). The trajectory of superior screws was directed at 20 to 30 degrees upward towards the contralateral pedicle. The trajectory of inferior screws was directed parallel to the upper endplate towards the contralateral pedicle. Source: Adapted from Sardhara et al.14

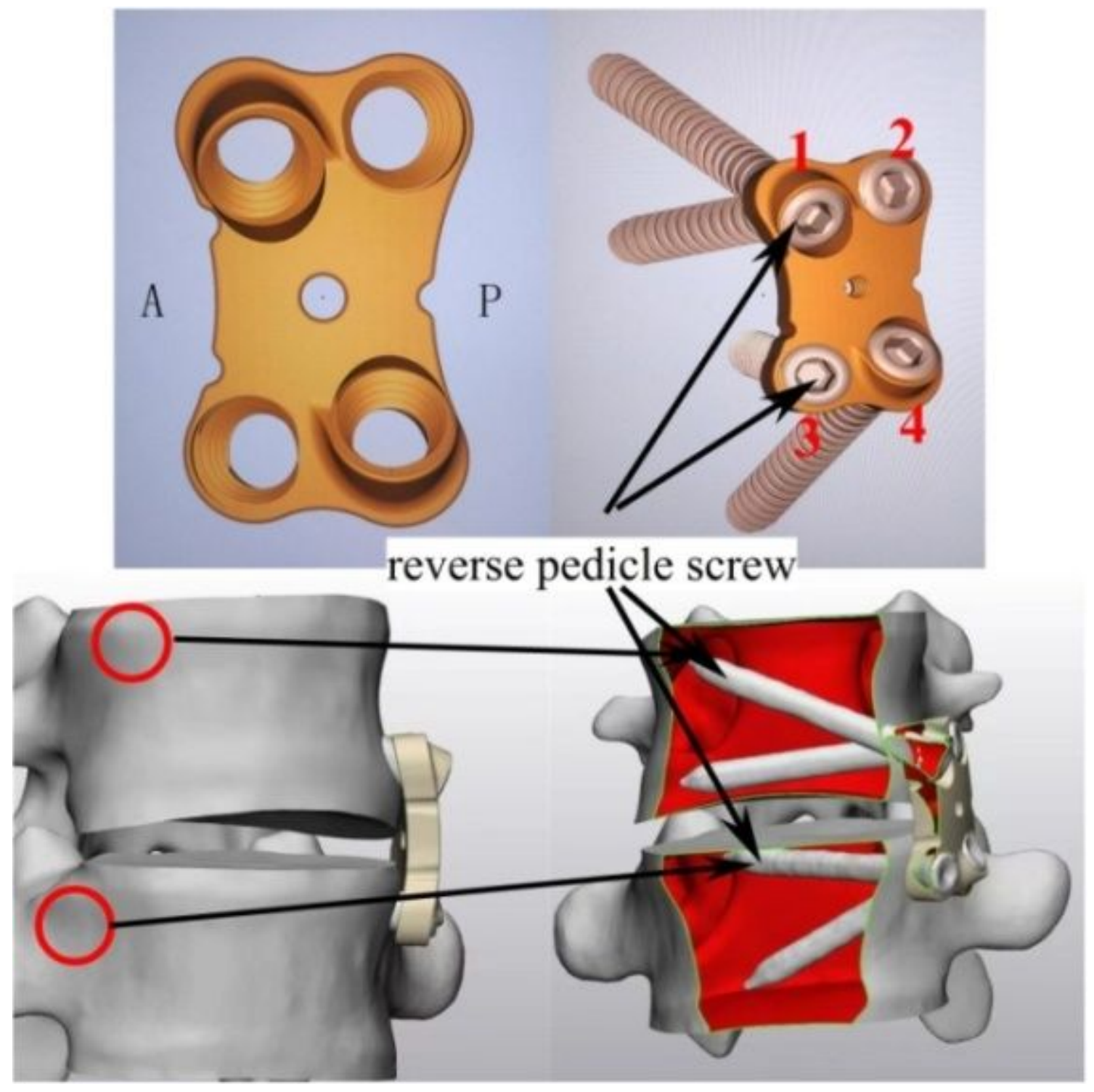

Figure 2

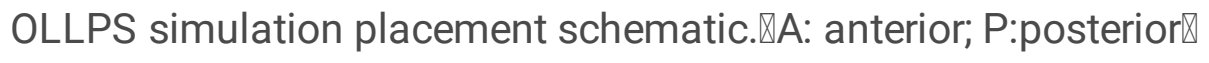




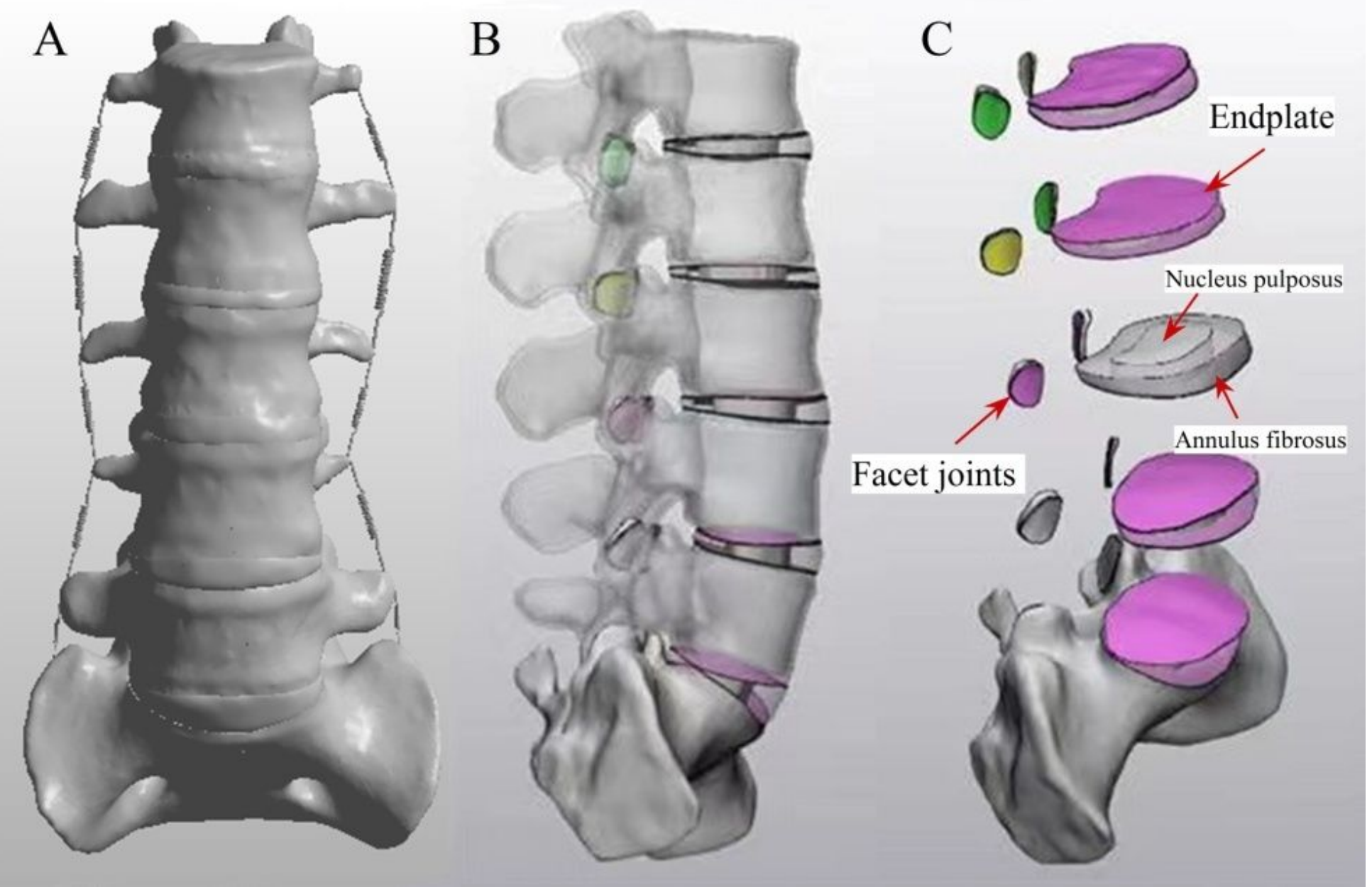

\section{Figure 3}

Detailed finite element model of lumbar spine L1-S1. (A) Anterior and (B) lateral view of the normal finite element model. $\mathbb{C} \otimes$ Facet joints, Endplate and Intervertebral disc.

\section{Figure 4}

Finite element model of OLIF with different internal fixations. (A) Intact; (B) stand-alone OLIF (SA); (C) OLIF with 2-screw lateral plate (LP-2); (D) OLIF with 4-screw lateral plate (LP-4); (E) OLIF with oblique lateral locking plate system (OLLPS); (F) OLIF with bilateral pedicle screw fixation (BPS). 
A

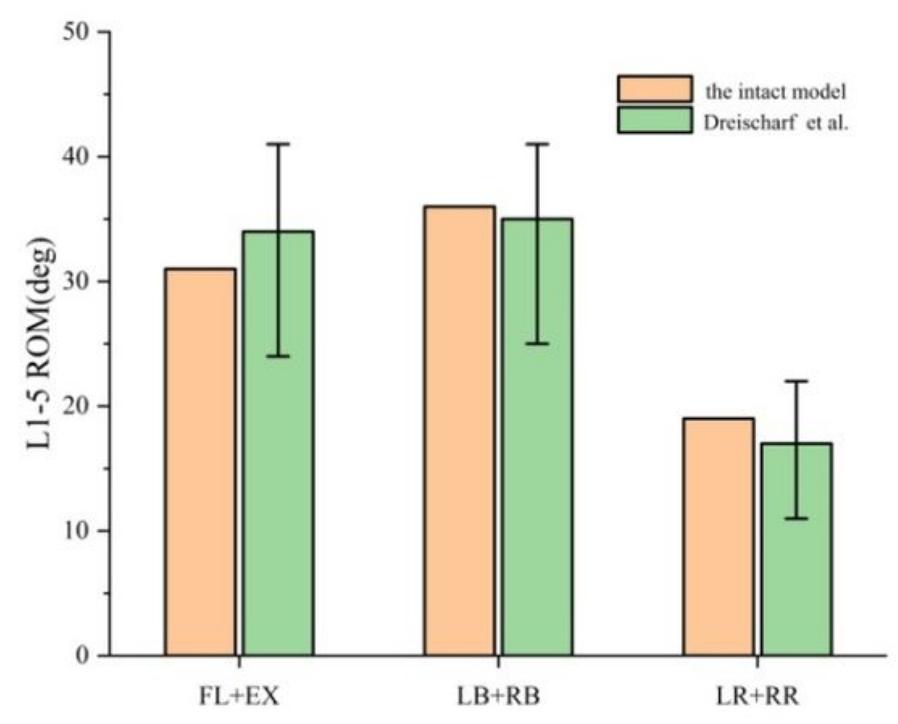

B

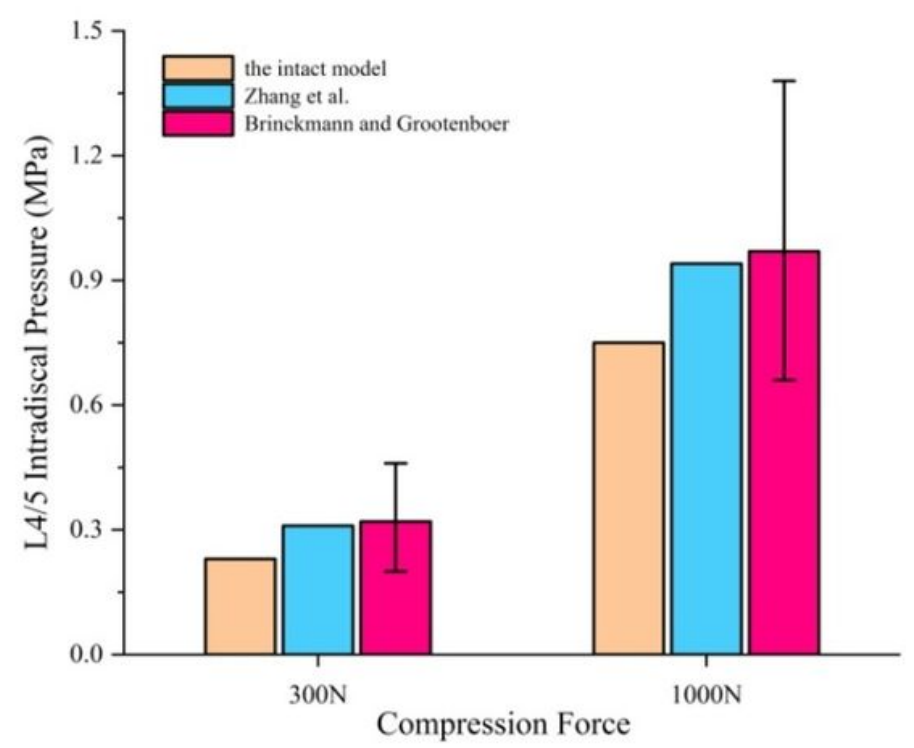

Figure 5

(A) Validation of computationally the intact model total L1-L5 range of motion under a pure moment of $7.5 \mathrm{~N} \cdot \mathrm{m}$. FL, flexion; $E X$, extension; LB, left bending; RB, right bending; LR, left rotation; RR, right rotation. Source: Adapted from Dreischarf et al.27 (B) Intradiscal pressure response validation comparing L4/5 results from the intact model to in vitro values from Brinckmann and Grootenboer28 and the results of finite element model responses investigated in Zhang et al.29 

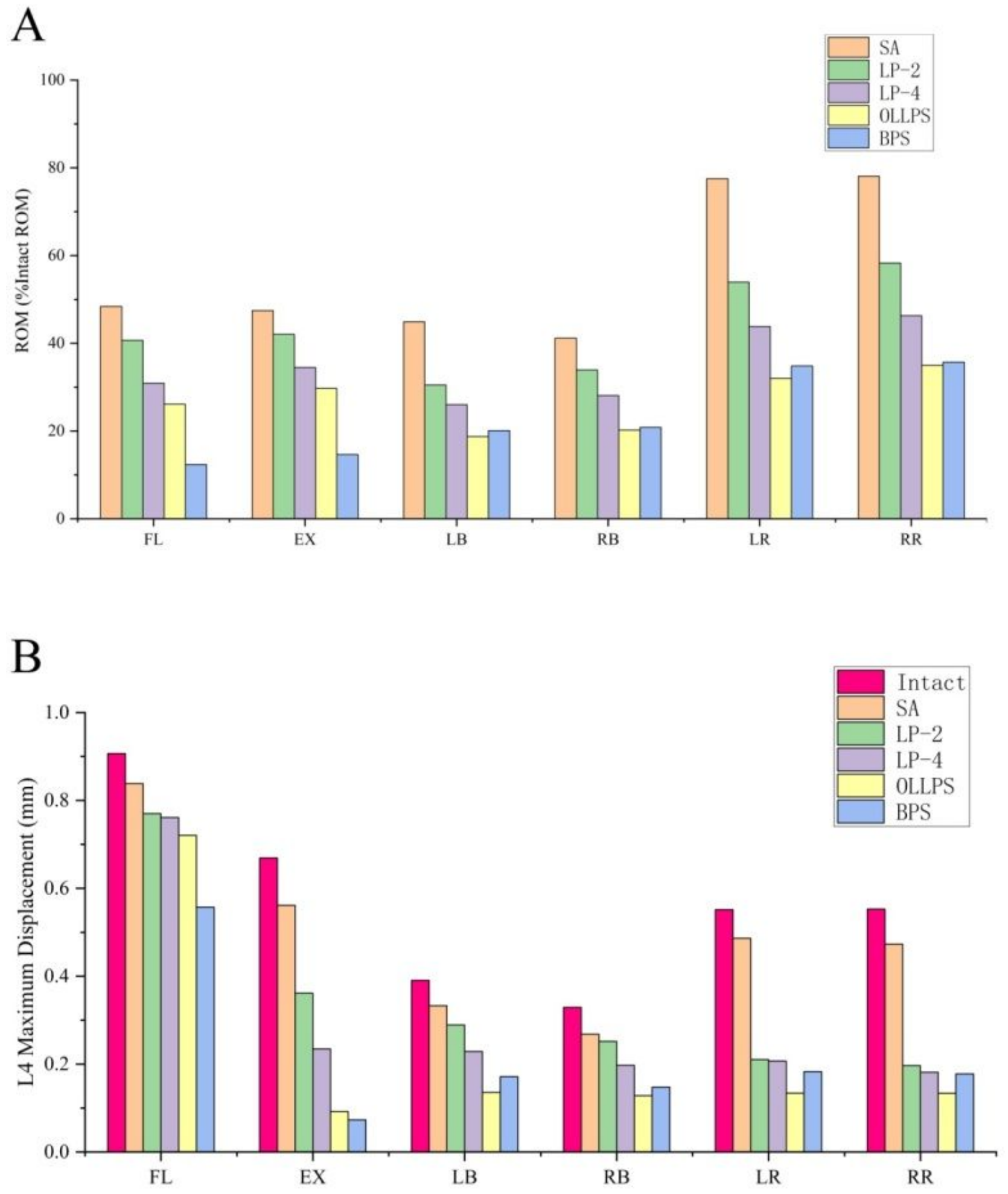

Figure 6

(A) ROM at the surgical level with various fixation options in six motion modes. (B) Maximum displacement of L4 with various fixation options in six motion modes. SA: stand-alone OLIF; LP-2: OLIF with 2-screw lateral plate; LP-4: OLIF with 4-screw lateral plate; OLLPS: OLIF with oblique lateral locking plate system; BPS: OLIF with bilateral pedicle screw fixation. 


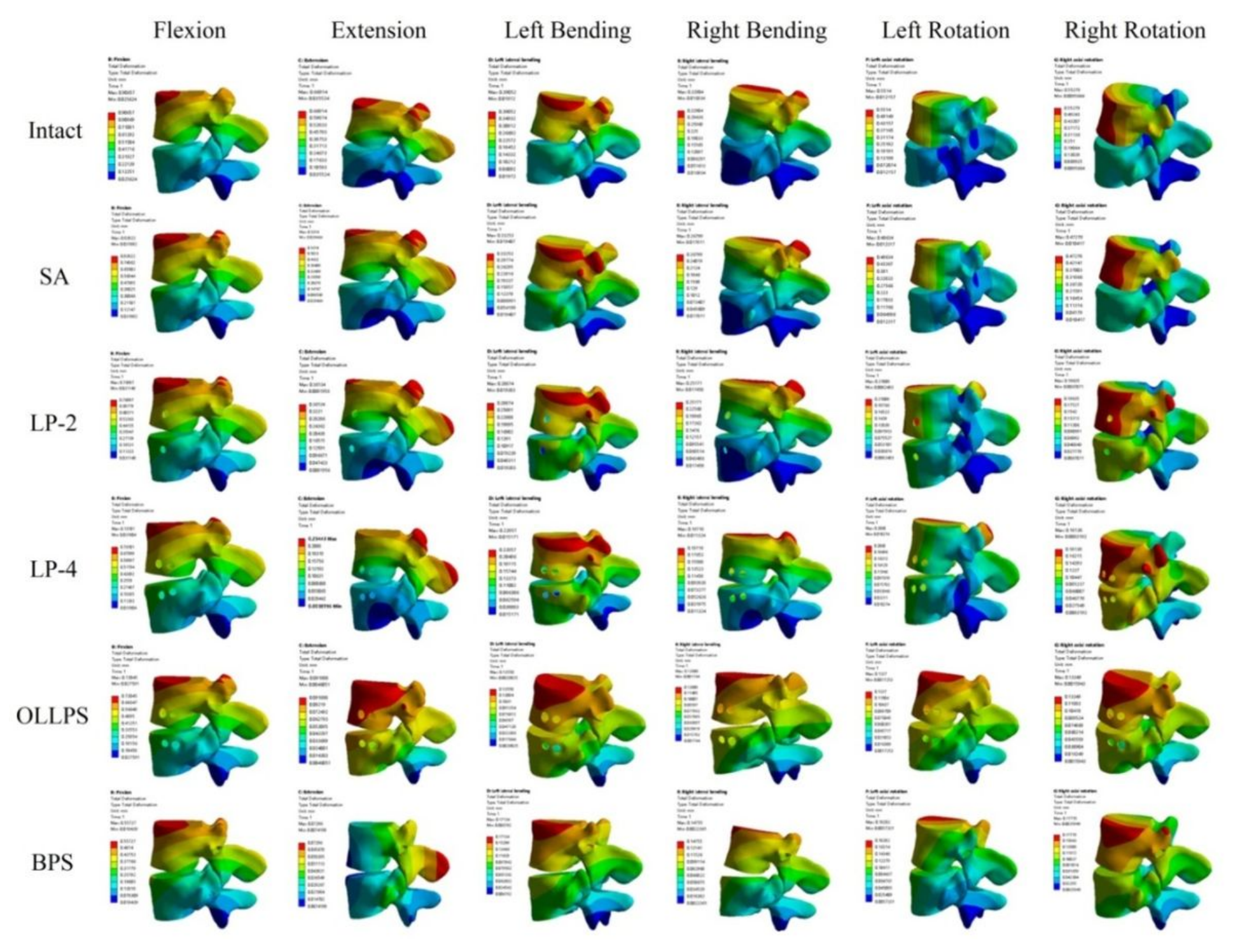

Figure 7

Maximum displacement nephogram of L4 with various fixation options in six motion modes. 


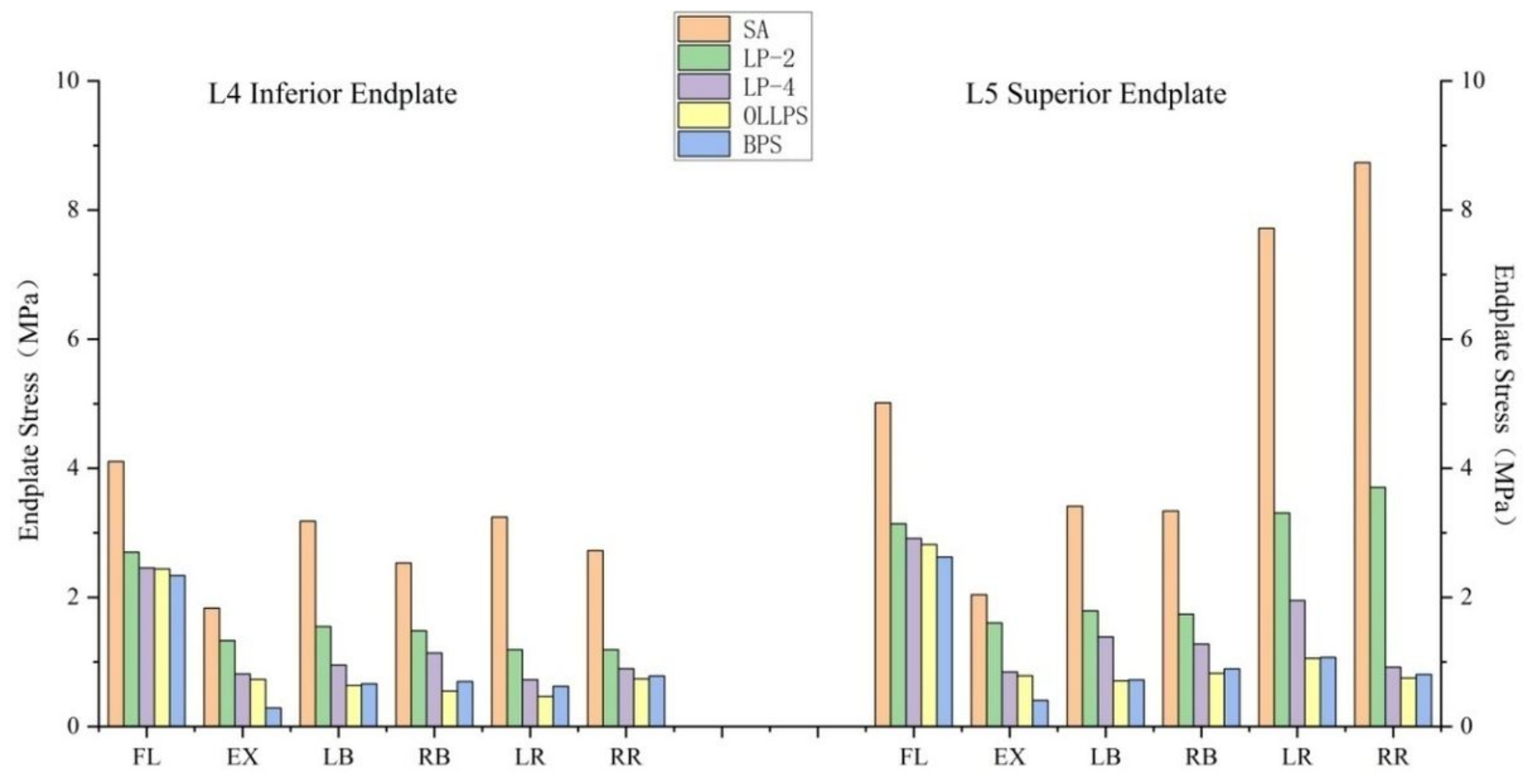

Figure 8

Maximum stress of the L4 inferior endplate and L5 superior endplate in six motion modes. 


\section{L5 Superior Endplate}

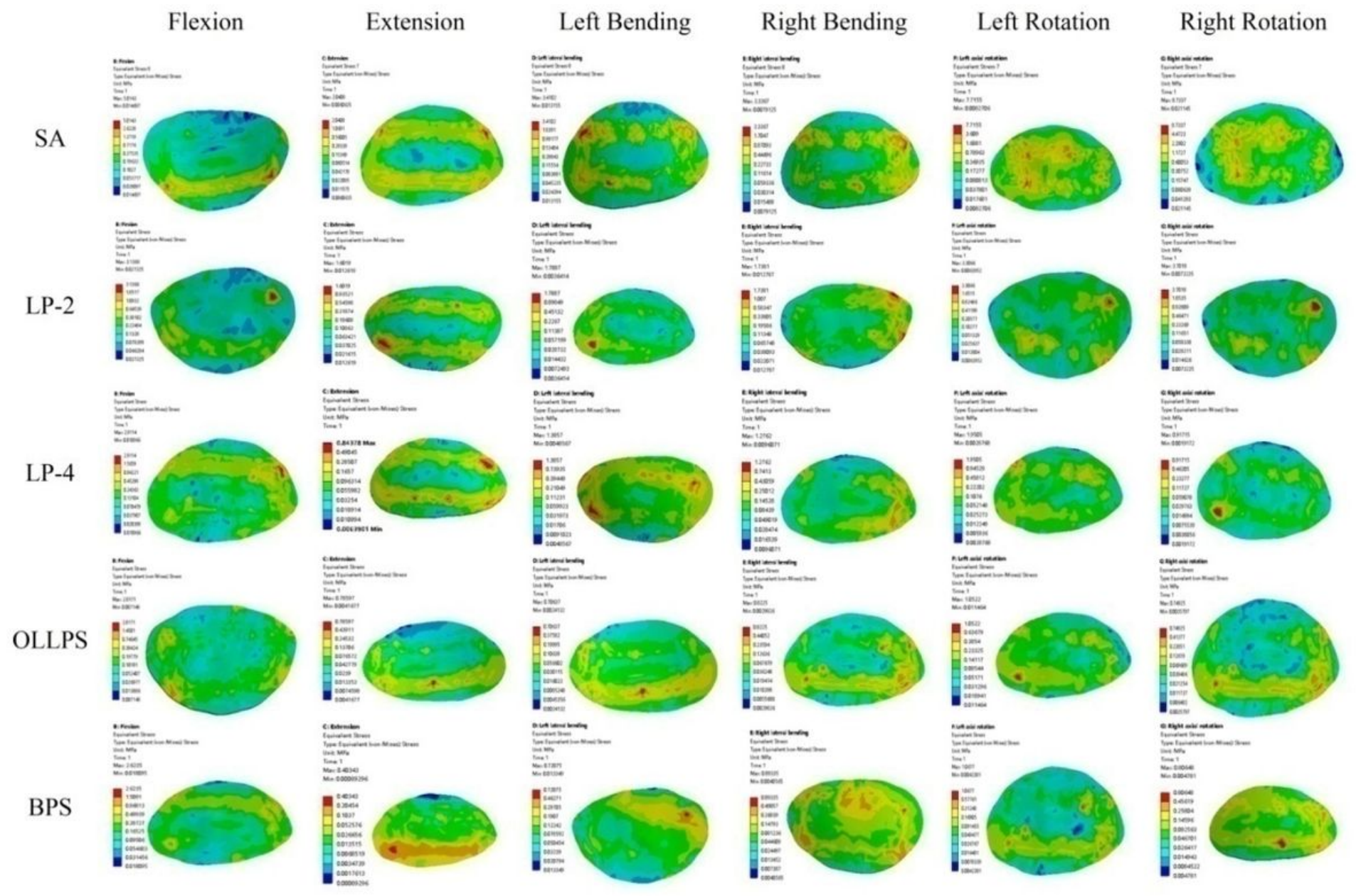

Figure 9

Stress distribution for the L5 superior endplate in six motion modes. 

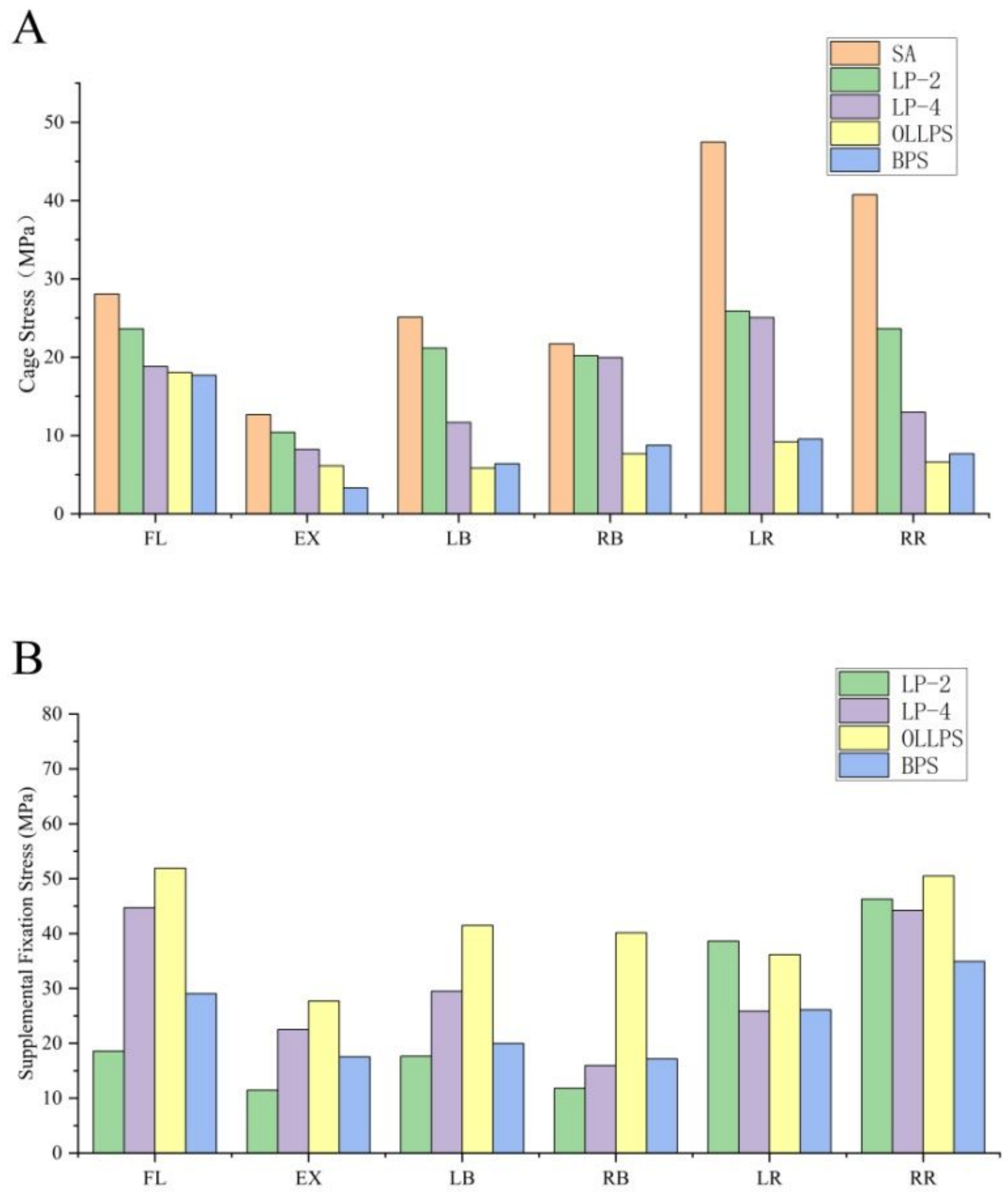

Figure 10

(A) Maximum stress of the cage with various fixation options in six motion modes. (B) Maximum stress of various fixation options in six motion modes. 


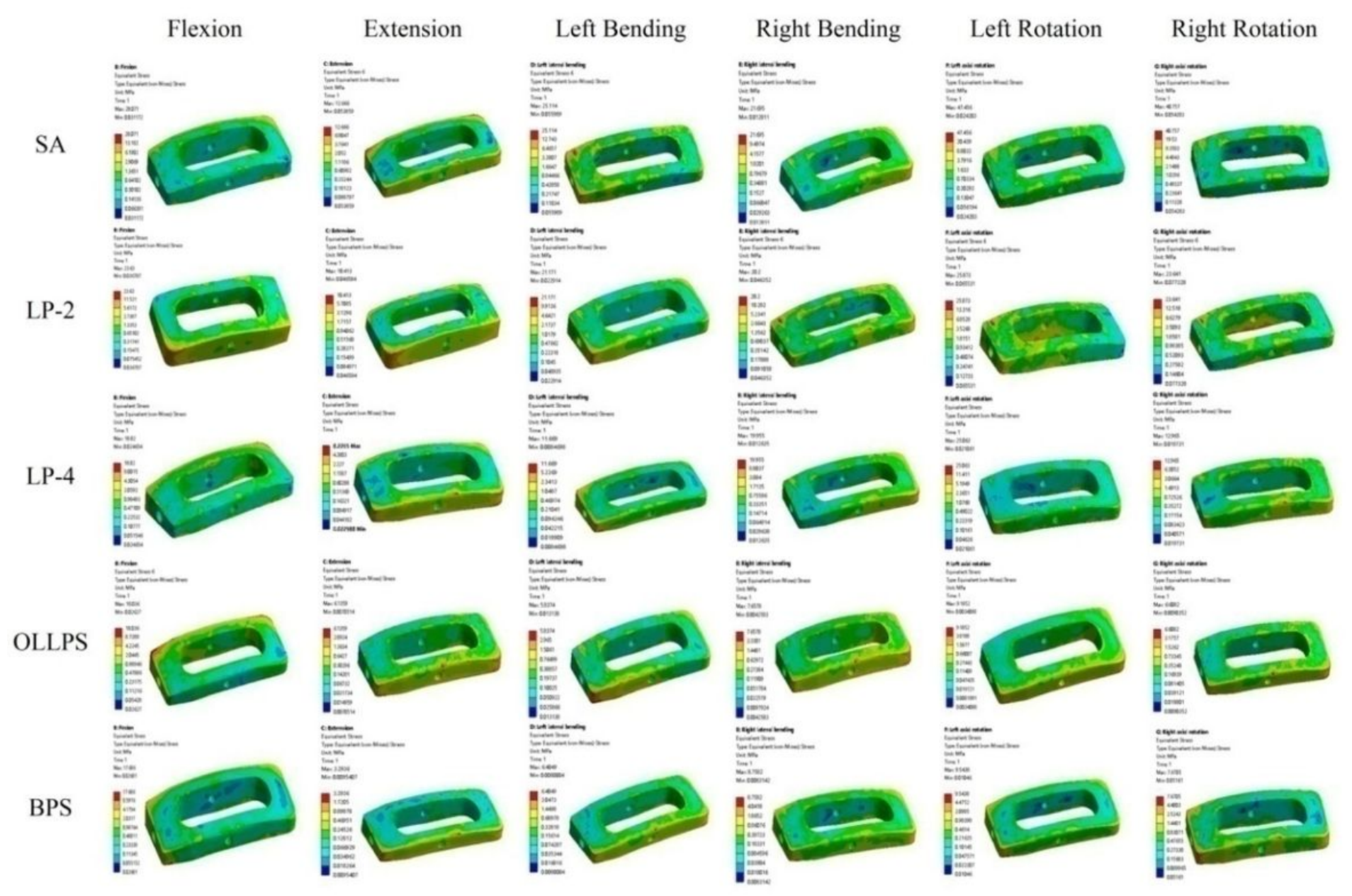

Figure 11

Stress distribution of the cage with various fixation options in six motion modes. 


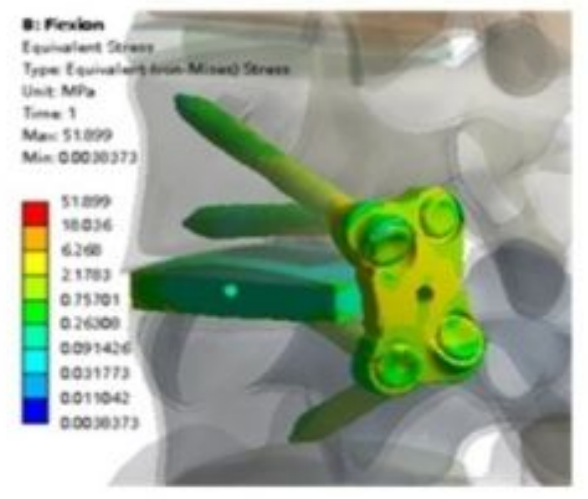

FL

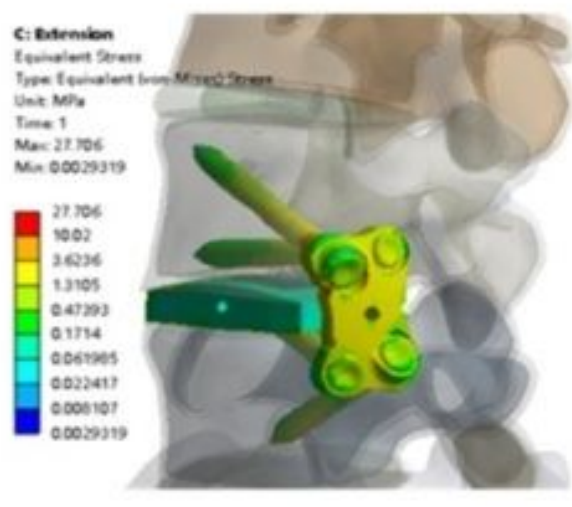

EX

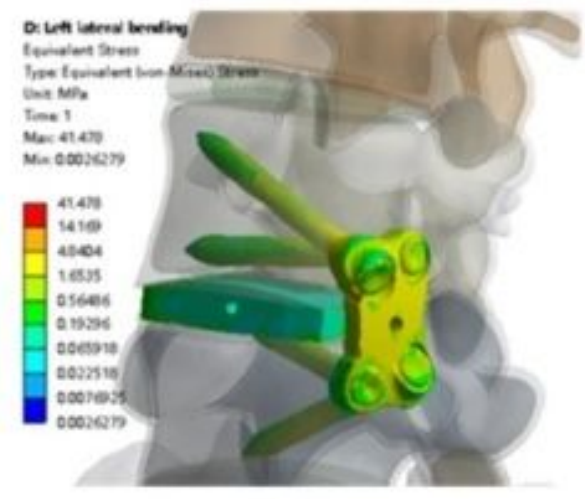

LB

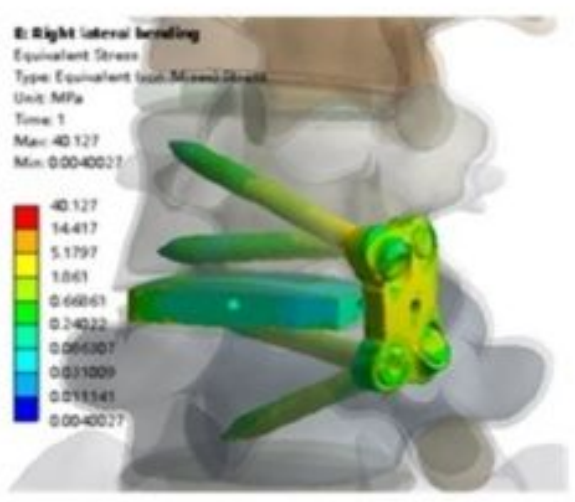

RB

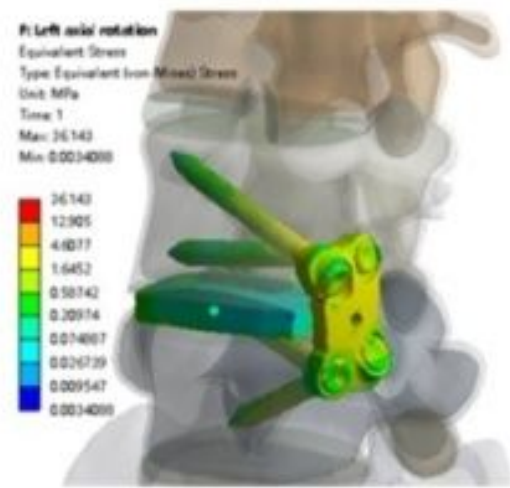

LR

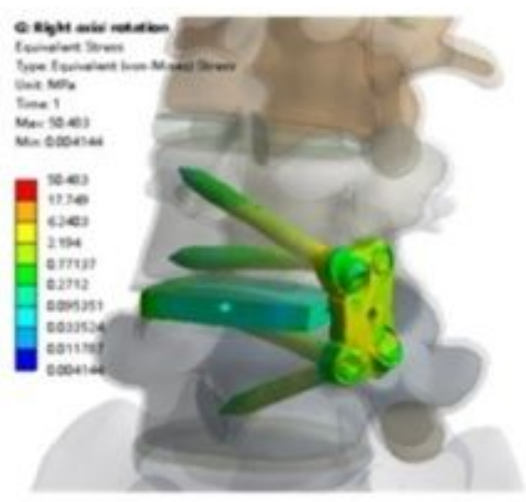

RR

Figure 12

Stress distribution of OLLPS in six motion modes. 